\title{
Aerosol forcing in the Climate Model Intercomparison Project (CMIP5) simulations by HadGEM2-ES and the role of ammonium nitrate
}

Article

Published Version

Bellouin, N., Rae, J., Jones, A., Johnson, C., Haywood, J. and Boucher, O. (2011) Aerosol forcing in the Climate Model Intercomparison Project (CMIP5) simulations by HadGEM2-ES and the role of ammonium nitrate. Journal of Geophysical Research - Atmospheres, 116 (D20). D20206. ISSN 01480227 doi: https://doi.org/10.1029/2011JD016074 Available at https://centaur.reading.ac.uk/30592/

It is advisable to refer to the publisher's version if you intend to cite from the work. See Guidance on citing.

To link to this article DOI: http://dx.doi.org/10.1029/2011JD016074

Publisher: American Geophysical Union

All outputs in CentAUR are protected by Intellectual Property Rights law, including copyright law. Copyright and IPR is retained by the creators or other copyright holders. Terms and conditions for use of this material are defined in the End User Agreement. 


\section{www.reading.ac.uk/centaur}

\section{CentAUR}

Central Archive at the University of Reading

Reading's research outputs online 


\title{
Aerosol forcing in the Climate Model Intercomparison Project (CMIP5) simulations by HadGEM2-ES and the role of ammonium nitrate
}

\author{
Nicolas Bellouin, ${ }^{1}$ Jamie Rae, ${ }^{1}$ Andy Jones, ${ }^{1}$ Colin Johnson, ${ }^{1}$ Jim Haywood, ${ }^{1,2}$ \\ and Olivier Boucher ${ }^{1}$ \\ Received 7 April 2011; revised 1 July 2011; accepted 3 August 2011; published 26 October 2011.
}

[1] The latest Hadley Centre climate model, HadGEM2-ES, includes Earth system components such as interactive chemistry and eight species of tropospheric aerosols. It has been run for the period 1860-2100 in support of the fifth phase of the Climate Model Intercomparison Project (CMIP5). Anthropogenic aerosol emissions peak between 1980 and 2020, resulting in a present-day all-sky top of the atmosphere aerosol forcing of -1.6 and $-1.4 \mathrm{~W} \mathrm{~m}^{-2}$ with and without ammonium nitrate aerosols, respectively, for the sum of direct and first indirect aerosol forcings. Aerosol forcing becomes significantly weaker in the 21 st century, being weaker than $-0.5 \mathrm{~W} \mathrm{~m}^{-2}$ in 2100 without nitrate. However, nitrate aerosols become the dominant species in Europe and Asia and decelerate the decrease in global mean aerosol forcing. Considering nitrate aerosols makes aerosol radiative forcing 2-4 times stronger by 2100 depending on the representative concentration pathway, although this impact is lessened when changes in the oxidation properties of the atmosphere are accounted for. Anthropogenic aerosol residence times increase in the future in spite of increased precipitation, as cloud cover and aerosol-cloud interactions decrease in tropical and midlatitude regions. Deposition of fossil fuel black carbon onto snow and ice surfaces peaks during the 20th century in the Arctic and Europe but keeps increasing in the Himalayas until the middle of the $21 \mathrm{st}$ century. Results presented here confirm the importance of aerosols in influencing the Earth's climate, albeit with a reduced impact in the future, and suggest that nitrate aerosols will partially replace sulphate aerosols to become an important anthropogenic species in the remainder of the 21 st century.

Citation: Bellouin, N., J. Rae, A. Jones, C. Johnson, J. Haywood, and O. Boucher (2011), Aerosol forcing in the Climate Model Intercomparison Project (CMIP5) simulations by HadGEM2-ES and the role of ammonium nitrate, J. Geophys. Res., 116, D20206, doi:10.1029/2011JD016074.

\section{Introduction}

[2] Aerosols are an active component of the Earth's atmosphere. They scatter and absorb shortwave and longwave radiation (direct radiative effect) and modify cloud microphysical properties and albedo, and hence impact precipitation (indirect radiative effects). Through those processes, anthropogenic aerosols exert direct and indirect forcings of the climate system, which have been estimated through modeling [e.g., Schulz et al., 2006] and constrained by observations [e.g., Bellouin et al., 2008; Quaas et al., 2008]. In addition, aerosols interact with other components of the Earth system. For instance, mineral dust aerosols are a

\footnotetext{
${ }^{1}$ Met Office, Hadley Centre, Exeter, UK.

${ }^{2}$ College of Engineering, Mathematics and Physical Sciences, University of Exeter, Exeter, UK.

Copyright 2011 by the American Geophysical Union. 0148-0227/11/2011JD016074
}

source of iron for ocean biogeochemistry [Jickells et al., 2005], deposition of mineral dust and black carbon aerosols decreases the albedo of snow and ice surfaces [Flanner et al., 2007], and aerosol impacts on photosynthetically active radiation influence vegetation growth [Mercado et al., 2009]. Finally, aerosols are an intricately coupled product of complex gas and aqueous phase atmospheric chemistry and hence impact the oxidizing capacity of the atmosphere. For these reasons, aerosol representations of increasing sophistication have been included in climate models.

[3] Estimates of aerosol direct and indirect radiative forcings of climate remain associated with large uncertainties. The latest Intergovernmental Panel on Climate Change (IPCC) Assessment Report [Forster et al., 2007] gives present-day estimates of $-0.50 \pm 0.40 \mathrm{~W} \mathrm{~m}^{-2}$ for the direct aerosol forcing and a best estimate of $-0.70 \mathrm{~W} \mathrm{~m}^{-2}$ for the first indirect aerosol forcing $(90 \%$ confidence range -1.1 to $+0.4 \mathrm{~W} \mathrm{~m}^{-2}$ ). The aerosol forcing is therefore likely to be weaker than the $+2.63 \mathrm{~W} \mathrm{~m}^{-2}$ forcing because of long-lived 
greenhouse gases in 2000, and Forster et al. [2007] give a best estimate for the present-day total anthropogenic radiative forcing of $+1.6 \mathrm{~W} \mathrm{~m}^{-2}$.

[4] The recent decrease in anthropogenic emissions of sulphur dioxide, the precursor to sulphate aerosols, means that nitrate is quickly becoming an important aerosol species, as evidenced in in situ aircraft observations over Europe [e.g., Haywood et al., 2008], and may continue doing so in the near future [Bauer et al., 2007]. Nitric acid competes with sulphate for the available ammonia to form ammonium nitrate and sulphate aerosols, and sulphuric acid is favored by its low vapor pressure. Decreases in sulphate precursors can therefore benefit ammonium nitrate formation [West et al., 1999]. Recent studies of the climate impacts of nitrate aerosols give diverse estimates of the regional importance and global burden of nitrate aerosols [van Dorland et al., 1997; Adams et al., 2001; Jacobson, 2001; Liao et al., 2004; Liao and Seinfeld, 2005; Myhre et al., 2006; Bauer et al., 2007]. In these studies, estimates of the nitrate aerosol direct radiative forcing vary by an order of magnitude, from -0.02 to $-0.2 \mathrm{~W} \mathrm{~m}^{-2}$. Variations in global nitrate burden and its partitioning between accumulation and coarse modes are the two main reasons for this large range of estimates.

[5] The response of the climate system to external forcings has an effect on the forcing agents. Aerosols will be affected by changes in temperature, winds, land use, precipitation and clouds, and atmospheric chemistry. Isaksen et al. [2009] review studies of climate-chemistry interactions and state that climate change tends to increase secondary aerosol production through increased levels of oxidants, to increase aerosol wet deposition through increased precipitation rates, and to affect emissions of biomass burning, mineral dust, DMS, and sea salt through changes in average weather. Racherla and Adams [2006] and Liao et al. [2009] obtain a decrease in aerosol burden of up to $20 \%$ when accounting for global warming because wet deposition rates increase in their climate simulations. Such a decrease in aerosol burden will decrease the aerosol radiative flux perturbation and exacerbate the warming trend.

[6] In this study, results from the historical and future climate simulations for CMIP5 are presented. The focus is on the evolution of total aerosol concentrations since 1860 and the resulting aerosol forcing, with a special emphasis on nitrate aerosols and their future evolution.

\section{HadGEM2-ES and CMIP5 Simulations}

[7] HadGEM2-ES is the Earth system model of the UK Met Office Hadley Centre [Collins et al., 2011; Jones et al., 2011]. The atmospheric resolution is N96 $\left(1.875^{\circ}\right.$ by $\left.1.25^{\circ}\right)$ with 38 vertical levels with the model top at $\sim 39 \mathrm{~km}$. The ocean resolution is $1^{\circ}$, increasing to $1 / 3^{\circ}$ at the equator, with 40 depth levels. HadGEM2-ES includes an interactive land and ocean carbon cycle as well as a dynamic vegetation model. An interactive tropospheric chemistry scheme is also included, which simulates the evolution of atmospheric composition and interactions with atmospheric aerosols. The model time step is $30 \mathrm{~min}$ for the atmosphere and land submodels and $1 \mathrm{~h}$ for the ocean submodel, with coupling between the atmosphere and the ocean every $24 \mathrm{~h}$.
[8] The HadGEM2-ES aerosol scheme is the Coupled Large-scale Aerosol Simulator for Studies In Climate (CLASSIC). This aerosol module contains numerical representation of up to eight tropospheric aerosol species: ammonium sulphate, mineral dust, sea salt, fossil fuel black carbon (FFBC), fossil fuel organic carbon (FFOC), biomass burning aerosols, secondary organic (also called biogenic), and ammonium nitrate aerosols. All species exert a direct radiative effect. All species except mineral dust and FFBC aerosols exert first and second indirect effects. A detailed description of those aerosol schemes and the relevant references are given in Appendix A.

[9] CMIP5 provides a framework for coordinated climate change experiments aimed at evaluating climate simulations of the recent past, providing projections of climate change, and quantifying climate feedbacks [Taylor et al., 2009]. Experiments include a historical simulation (1860-2005) forced by observed concentrations of long-lived greenhouse gases and reconstructed aerosol emissions, as well as solar and volcanic forcings. The historical emissions for tropospheric aerosols and aerosol precursors are described by Lamarque et al. [2010]. Climate change projections start from the end of the historical simulation and are driven by four future scenarios, termed representative concentration pathways (RCPs) [Moss et al., 2010]. The scenarios are labeled RCP3-PD (peak and decline) [van Vuuren et al., 2007], RCP4.5 [Clarke et al., 2007], RCP6.0 [Fujino et al., 2006], and RCP8.5 [Riahi et al., 2007]. Finally, a control experiment covering 1860-2100 is also undertaken, in which no external forcing, either anthropogenic or natural, is applied to the model. The control experiment remains on average at radiative balance at the top of the atmosphere and does not exhibit any drift in the simulated climate and aerosol burdens. Variability in the control experiment only comes from the internal variability of the climate system. By 2100 , globally averaged near-surface temperatures have increased by $1.8 \mathrm{~K}$ (RCP3-PD), 2.9 K (RCP4.5), 3.6 K (RCP6.0), and 5.4 K (RCP8.5) compared to the control experiment.

[10] Nitrate aerosol is not included in the main simulations, as the scheme was still in development when the control simulation started. However, nitrate has been added in parallel simulations, which typically start from the main simulations at various points in their evolution and run for 5 years, a configuration hereafter termed "time slice" experiments. Time slice experiments initialized from the main historical simulations start in 1860, 1950, 1980 and 2000. Time slice experiments initialized from RCP simulations start in 2030 and 2090 and are performed for each of the four RCPs.

\subsection{Aerosol Emissions}

[11] Data sets required by HadGEM2-ES for tropospheric aerosol modeling are emissions of sulphur dioxide $\left(\mathrm{SO}_{2}\right)$, land-based dimethyl sulphide (DMS), ammonia $\left(\mathrm{NH}_{3}\right)$, and primary black and organic carbon aerosols from fossil fuel combustion and biomass burning. Emissions for sea-salt and mineral dust aerosols, and ocean-based DMS emissions, are computed interactively so emission data sets are not required. In addition, the UKCA tropospheric chemistry scheme (F. O'Connor et al., Evaluation of the new UKCA climatecomposition model. Part II: The troposphere, manuscript in 

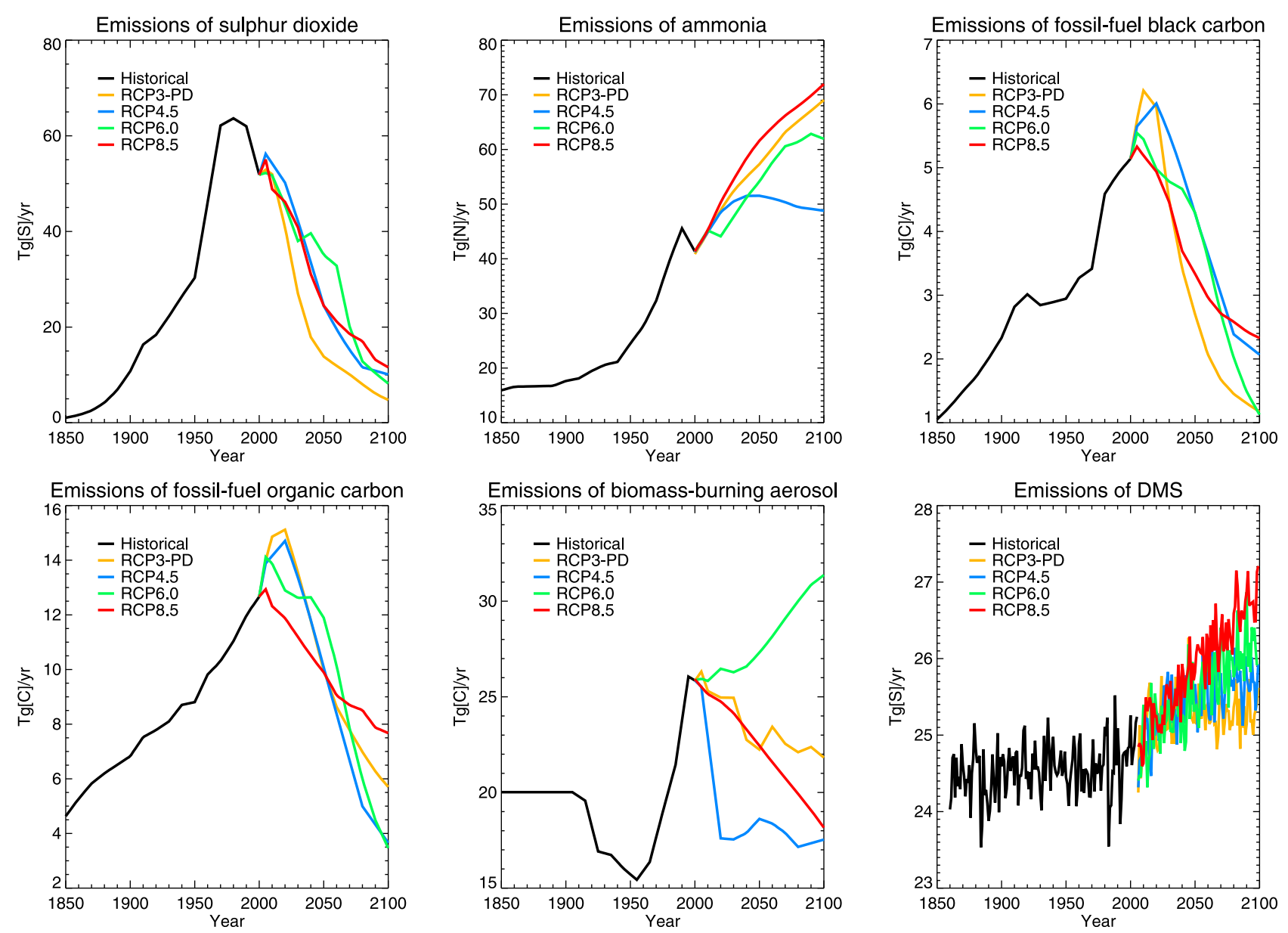

Figure 1. Time series of global and annual averaged emissions of sulphur dioxide, ammonia, fossil fuel black carbon aerosols, fossil fuel organic carbon aerosols, biomass burning aerosols, and dimethyl sulfide (DMS), according to CMIP5 emission data sets or simulations. Historical period is shown in black, and the four representative concentration pathways are shown in color.

preparation, 2011), which provides oxidants to the aerosol schemes, requires emissions of $\mathrm{NO}_{2}, \mathrm{CH}_{4}, \mathrm{CO}, \mathrm{HCHO}, \mathrm{C}_{2} \mathrm{H}_{6}$, $\mathrm{C}_{3} \mathrm{H}_{8},\left(\mathrm{CH}_{3}\right)_{2} \mathrm{CO}$, and $\mathrm{CH}_{3} \mathrm{CHO}$. CMIP5 data sets provide the anthropogenic emissions required by the model and, for some species, have to be complemented by natural emissions.

[12] Emissions of $\mathrm{SO}_{2}$ are injected at the surface, except for emissions for the energy sector and half of industrial emissions which are injected at $0.5 \mathrm{~km}$ to represent chimney-level emissions. $\mathrm{SO}_{2}$ emissions from biomass burning are not included since CLASSIC includes a separate scheme for biomass burning aerosol. Since most of the $\mathrm{SO}_{2}$ emitted during biomass burning events is oxidized and condenses quickly onto biomass burning particles [Formenti et al., 2003], inclusion of $\mathrm{SO}_{2}$ emissions from biomass burning would imply an element of double counting and has been ignored here. To represent $\mathrm{SO}_{2}$ emissions from noneruptive volcanoes, the three-dimensional data set by Andres and Kasgnoc [1998] is added to CMIP5 distributions. It yields a rate of $7.38 \mathrm{Tg}[\mathrm{S}] \mathrm{yr}^{-1}$ on a global average, independent of the year simulated. Land-based DMS emissions are taken from Spiro et al. [1992] and provide $0.86 \mathrm{Tg}^{\mathrm{SS}} \mathrm{yr}^{-1}$.

[13] Emissions of $\mathrm{NH}_{3}$ are injected at the surface. As with $\mathrm{SO}_{2}, \mathrm{NH}_{3}$ emissions from biomass burning are not included. To represent natural sources, data sets for $\mathrm{NH}_{3}$ emissions by wild animals, natural soils, and the ocean [Bouwman et al., 1997] are added to the CMIP5 distributions. They provide a globally averaged rate of $\left.10.56 \mathrm{Tg}^{\mathrm{N}}\right] \mathrm{yr}^{-1}$, independent of the year simulated.

[14] Emissions of carbonaceous aerosols are purely anthropogenic and thus the CMIP5 data sets do not need to be complemented by other sources. Emissions of primary fossil fuel and biofuel black and organic carbon are injected at $80 \mathrm{~m}$. Emissions of biomass burning aerosols are the sum of the biomass burning emissions of black and organic carbon. Grassfire emissions are assumed to be located at the surface, while forest fire emissions are injected homogeneously across the boundary layer $(0.8-2.9 \mathrm{~km})$.

[15] Time series of global emissions of $\mathrm{SO}_{2}, \mathrm{NH}_{3}, \mathrm{FFBC}$ and FFOC aerosols, biomass burning aerosols, and DMS are shown in Figure 1. Global emissions of $\mathrm{SO}_{2}$ peak first in 1980, when emissions peak in Europe, then again in 2020, when emissions peak in Asia, before declining at a fast rate until 2100 , when emissions will only be 5-10 times emissions in 1850. Emissions of $\mathrm{NH}_{3}$ increase continuously from 1850 to 2100 in all RCPs, except RCP4.5 where emissions remain close to $50 \mathrm{Tg}[\mathrm{N}] \mathrm{yr}^{-1}$ throughout the 21 st century. The agricultural sector provides most of the changes in $\mathrm{NH}_{3}$ emissions, and growth in emissions comes with the growth 
in population and biofuel production. Emissions from Europe remain approximately constant in RCP3-PD and RCP4.5 but increase in RCP6.0 and RCP8.5. Emissions from Asia, Africa, and South America increase in all scenarios. Emission of FFBC and FFOC aerosols increase strongly between 1850 and the present day, peak between 2005 and 2020 depending on the RCP, and decline to 1850 (RCP3-PD, RCP6.0) or 1900 (RCP4.5, RCP8.5) levels by 2100. Emissions of biomass burning aerosols are constant for the period 1850-1900 in the CMIP5 historical data set, and decrease between 1900 and 1950. This decrease of $5 \mathrm{Tg}$ [C] $\mathrm{yr}^{-1}$ is due to the suppression of biomass burning emissions in the southeastern United States. From 1950 to 2000, biomass burning emissions increase again, driven by human activities in South America and Africa. After 2000, RCPs differ in projecting biomass burning trends. RCP6.0 is the only scenario including an increase in emissions, while the other three RCPs show a decline of varying magnitude. Finally, DMS emissions increase throughout the 1860-2100 period. Over ocean, they are provided by the interactive biogeochemistry. In the parameterization used in HadGEM2$\mathrm{ES}$, an increase in sea surface temperature has competing effects on DMS emissions. On the one hand, ocean nutrients are reduced, decreasing phytoplankton biomass and hence DMS emissions. On the other hand, the ocean mixed-layer depth decreases, concentrating DMS into a more shallow layer and increasing DMS emissions into the atmosphere. The second effect typically dominates. In addition, changes in near-surface wind speed, discussed in section 3.3, affect DMS emissions. In simulations where $\mathrm{CO}_{2}$ concentrations are increased by $1 \%$ per year to 4 times their value for 1860 and where DMS concentrations in seawater remain fixed at 1860 levels, emissions increase by $5 \%$ over 140 years. When the ocean biogeochemistry model is activated and provides interactive DMS concentrations, emissions increase by $11 \%$. This suggest that half the increase is due to changes in wind speed and temperature while the other half is attributable to ocean chemistry, although the combined effect is very likely nonlinear [Thomas et al., 2011]. Overall, in the CMIP5 simulations, DMS emissions in 2100 are $2.5 \%-10 \%$ larger than 1860 emissions, depending on the scenario. This increase scales with the change in global mean near-surface temperature.

\subsection{Validation of Modeled Aerosols}

[16] The historical CMIP5 simulation provides the opportunity to validate important aspects of aerosol modeling in HadGEM2-ES. Here, validation focuses on four metrics that are important for the subsequent analysis: sulphate $\left(\mathrm{SO}_{4}\right)$ aerosol surface concentrations, as sulphate is the dominant aerosol species in industrialized countries during the historical period; nitrate $\left(\mathrm{NO}_{3}\right)$ aerosol surface concentrations, as nitrate is a specific focus of this paper; black and organic carbon aerosol surface concentrations, as carbonaceous aerosols have unique absorbing properties; and total aerosol optical depth (AOD), as it measures the columnintegrated aerosol extinction and relates to the aerosol direct effect. A fifth metric, cloud condensation nuclei, would also be of interest as it relates to indirect effects, but observational data sets remain too sparse to be used for validation. Modeled and observational data used in the validation are monthly means for the period 1998-2002 unless otherwise stated. Modeled values are taken in the grid box containing the observation site and, for surface concentrations, at the model level containing the site altitude if it is different from the grid box mean orography.

[17] Aerosol surface concentrations are provided by the European Monitoring and Evaluation Programme (EMEP) [Hjellbrekke, 2002], Clean Air Status and Trends Network (CASTNET) [Mueller, 2003], and Interagency Monitoring of Protected Visual Environments (IMPROVE) [Malm et al., 1994]. EMEP covers Europe while CASTNET and IMPROVE cover North America. Sites used for validation are those providing valid monthly means for all months in the 5 year period 1998-2002. For $\mathrm{SO}_{4}$, there are 33 EMEP sites, 17 CASTNET sites, and 44 IMPROVE sites matching these criteria. For $\mathrm{NO}_{3}$, the numbers are 11,17 , and 35, respectively. For black and organic carbon aerosols, IMPROVE provides 35 sites. EMEP provides 12 sites that only cover June 2002 to July 2003 when a dedicated campaign measuring carbonaceous aerosol concentrations was undertaken. Measurements are for total elemental carbon and total organic carbon. Modeled concentrations of black carbon include FFBC and $5.4 \%$ of biomass burning aerosol mass, following the assumed mass fraction of $\mathrm{BC}$ in the biomass burning tracer used in deriving the optical properties of aged biomass burning aerosols. Modeled concentrations of organic carbon include FFOC, the remaining fraction of biomass burning, and secondary organic aerosols. Total AODs are given at $0.44 \mu \mathrm{m}$ by the Aerosol Robotic Network (AERONET) [Holben et al., 2001], with 67 sites worldwide providing valid monthly means at quality control level 2.0 in the period 1998-2002.

[18] Results are shown in Figure 2 as scatterplots of seasonal mean values with different symbols indicating European and North American sites for surface aerosol concentrations. Sulphate aerosol surface concentrations are underestimated in Northern Hemisphere winter. In summer, concentrations are overestimated at central and eastern European sites. In spite of these limitations, overall performance is good, and alike in Europe and North America. Nitrate aerosol concentrations are overestimated from spring to autumn, but a large fraction of sites remain within a factor 2 of the measurements. In winter, concentrations are overestimated in the western United States. In Figure 2, this translates into a cluster of points where measurements of nitrate concentrations are below $0.2 \mu \mathrm{g}[\mathrm{N}] \mathrm{m}^{-3}$ while the model covers the range 0.2 to $0.7 \mu \mathrm{g}[\mathrm{N}] \mathrm{m}^{-3}$. Carbonaceous aerosol concentrations compare well against measurements, at least in source regions. Model skill in simulating FFBC in the Arctic is discussed in section 4.3. The organic carbon component is strongly underestimated by the model in winter and spring when FFOC is the main source of organic carbon. With the increase in mass of secondary organic aerosols from isoprene emissions in summer and autumn, the comparison against observations improves. The comparison of modeled and measured total AODs is good, except where the model overestimates the mineral dust AOD. Figure 2 shows, by representing sites where mineral dust dominates the modeled AOD with different symbols, that total AOD at these sites can be overestimated by factors greater than 2 during the local dusty season. The comparison against AERONET is shown in more detail in Figure 3, which shows the 5 year averaged distribution of total AOD at $0.44 \mu \mathrm{m}$ for 1998-2002, 
Sulphate aerosol surface concentration
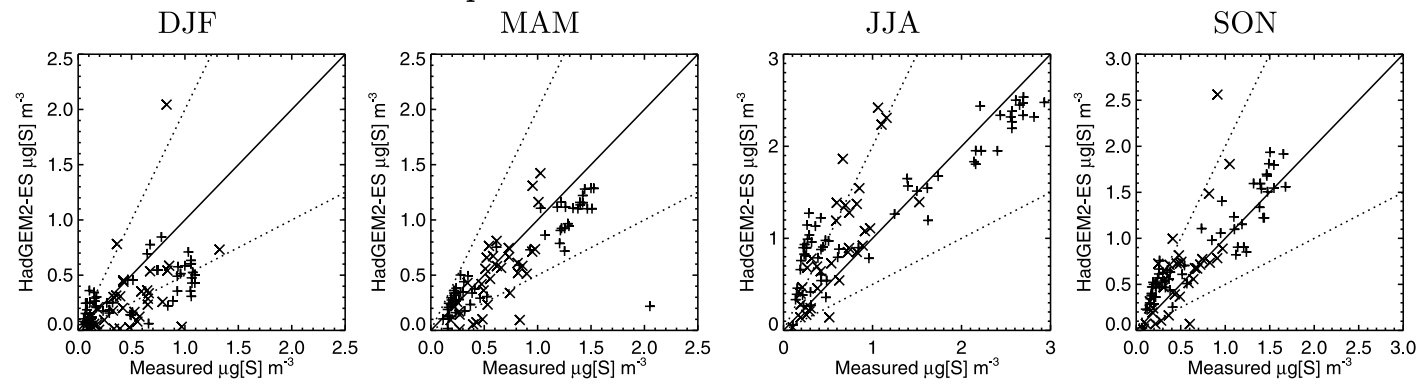

Nitrate aerosol surface concentration
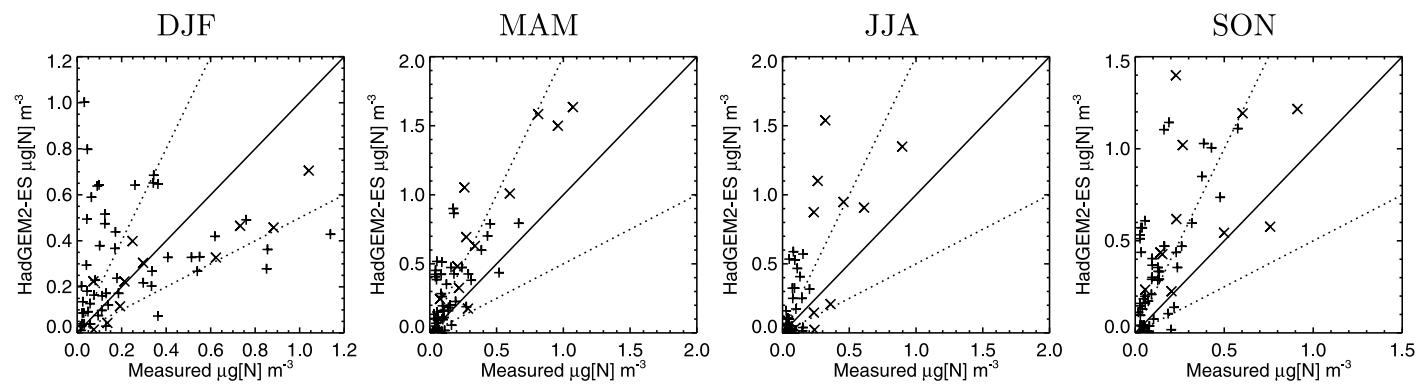

Black-carbon aerosol surface concentration
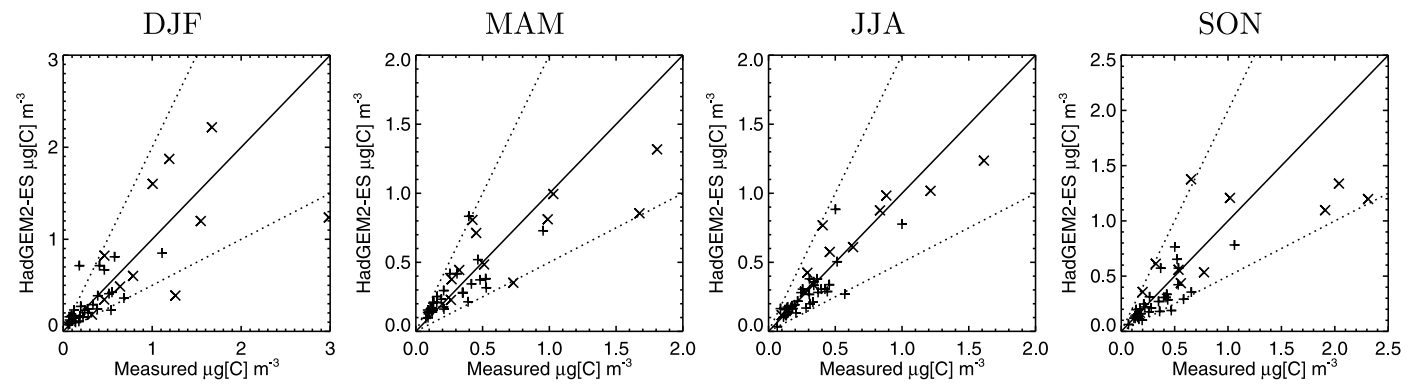

Organic-carbon aerosol surface concentration
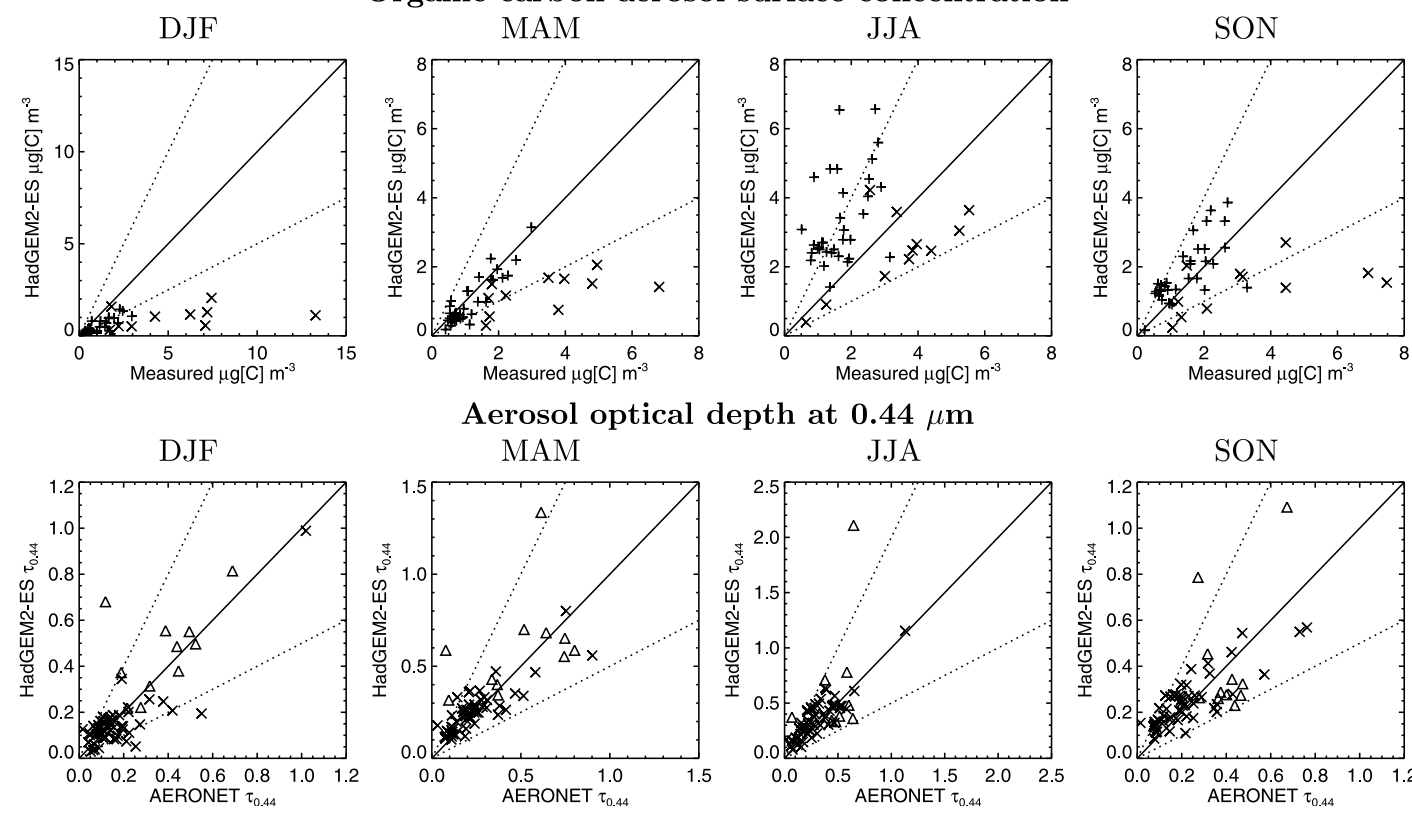

Aerosol optical depth at $0.44 \mu \mathrm{m}$ MAM

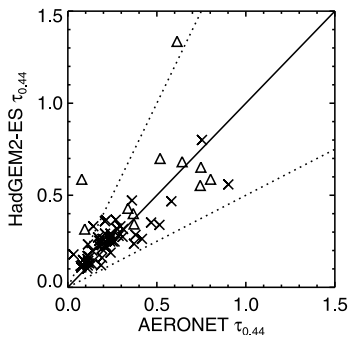

JJA

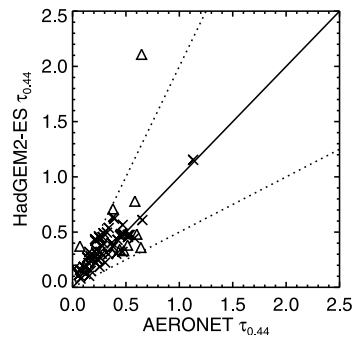

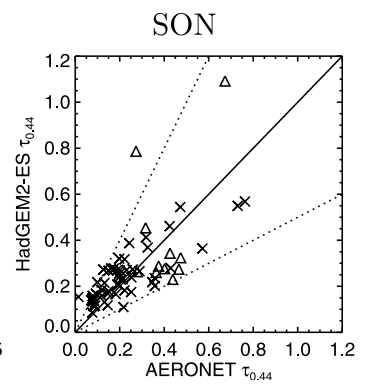

Figure 2. Component aerosol surface concentrations and total aerosol optical depth at $0.44 \mu \mathrm{m}$ as simulated by HadGEM2-ES and measured by ground-based networks, presented as seasonal averages over the period 1998-2002. The 1:1 line is shown as a solid line, with 1:2 and 2:1 lines shown as dashed lines. For surface concentrations, crosses and plus signs indicate European and North American networks, respectively. For aerosol optical depth, triangles indicate sites where mineral dust aerosols dominate the modeled aerosol optical depth. 


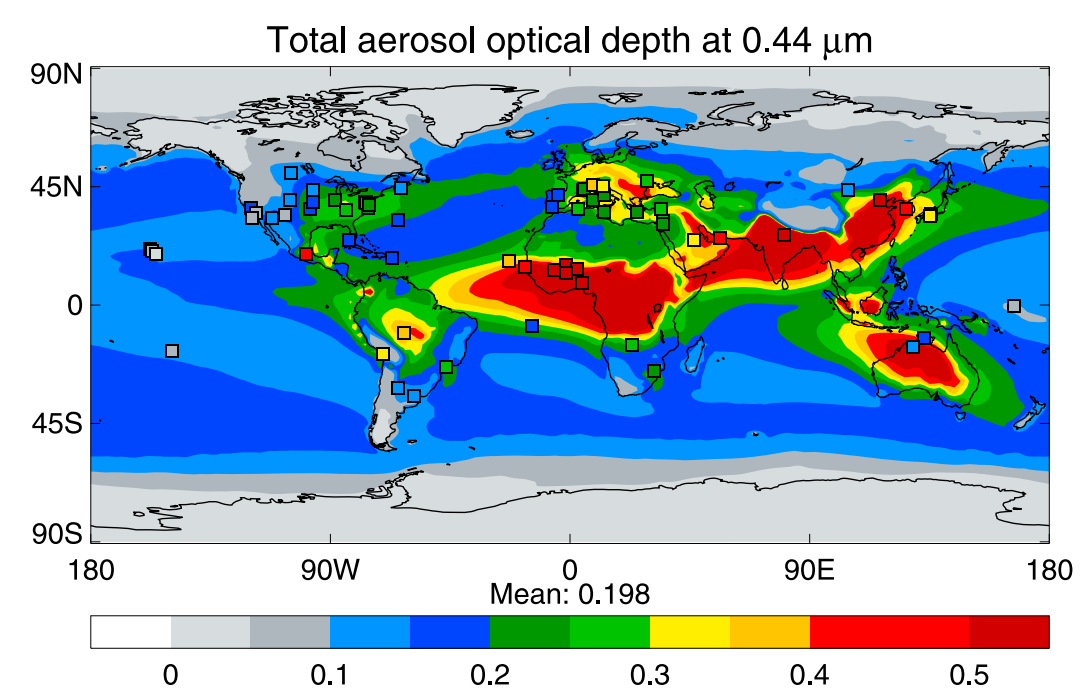

Figure 3. Distribution of total aerosol optical depth at $0.44 \mu \mathrm{m}$ as simulated by HadGEM2-ES averaged over the period 1998-2002. Square boxes show averaged Aerosol Robotic Network (AERONET) measurements for the same period and using the same color scale.

including nitrate AOD, with AERONET averages overlaid. HadGEM2-ES reproduces the known patterns of AOD, with industrial pollution in North America, Europe, and Asia, biomass burning aerosols in Central Africa and South America, and mineral dust transport across the Atlantic and Arabian Sea. The eastward gradient in AOD in North America and China is well reproduced. The model overestimates AODs in Central and Eastern Europe. The very large mineral dust AODs over Australia are due to poor simulations of bare soil fraction and soil moisture, causing large mineral dust emissions.

\section{Aerosols in CMIP5 Simulations}

\subsection{Present-Day Aerosols}

[19] Table 1 summarizes key aerosol characteristics in the HadGEM2-ES historical run for the period 1998-2002. Most values are within the ranges simulated by aerosol models participating in the AeroCom intercomparison project [Textor et al., 2006]. Mineral dust and FFBC aerosols behave differently than in the AeroCom models, however. Huneeus et al. [2010] compare mineral dust aerosol simulations in 15 AeroCom models. Model variability is large: mineral dust emissions range from 500 to $4400 \mathrm{Tg} \mathrm{yr}^{-1}$ and $\mathrm{AOD}$ at $0.55 \mu \mathrm{m}$ covers $0.010-0.053$ with most models between 0.020 and 0.035 . Mineral dust in HadGEM2-ES is characterized with emissions above $8000 \mathrm{Tg} \mathrm{yr}^{-1}$ for particle sizes of 0.03 to $30 \mu \mathrm{m}$, and an AOD of 0.060: on both counts, HadGEM2-ES is outside the AeroCom ranges. The magnitude of emission fluxes depends on particle sizes, and most AeroCom models included in the intercomparison only cover particles sizes of less than $10 \mu \mathrm{m}$. In that size range, HadGEM2-ES mineral dust emissions are $3311 \pm$ $227 \mathrm{Tg} \mathrm{yr}^{-1}$, a value more in line with the AeroCom models. However, the relative importance of emitting regions differ between HadGEM2-ES and the AeroCom models. In HadGEM2-ES, the Sahara desert emits $43 \%$ of global emissions. Huneeus et al. [2010] get $71 \%$ of global emissions from North Africa. The discrepancy comes from large emissions from other regions in HadGEM2-ES, which reduce the relative contribution of Saharan emissions. Australia represents $26 \%$ of global emissions, compared to only $3 \%$ in the models compared by Huneeus et al. [2010], while a further $10 \%$ comes from the Thar desert in the northwestern Indian state of Rajasthan. The large mineral dust optical depths simulated in those two regions are not supported

Table 1. Characterization of Aerosols in HadGEM2-ES CMIP5 Historical Simulation Over the Period 1998-2002: Emissions of Aerosol Precursor $\left(\mathrm{SO}_{2}\right.$ for Sulphate and $\mathrm{NO}_{x}$ for Nitrate) or Primary Aerosol, Burden, Residence Time, Percentage of Total Deposition Due to Dry Deposition, Total Mass in the Atmosphere, and Aerosol Optical Depth (AOD) at $0.55 \mu \mathrm{m}^{\mathrm{a}}$

\begin{tabular}{|c|c|c|c|c|c|c|}
\hline Aerosol Species & $\begin{array}{l}\text { Emissions } \\
\left(\mathrm{Tg} \mathrm{yr}^{-1}\right)\end{array}$ & $\begin{array}{c}\text { Burden } \\
\left(\mathrm{mg} \mathrm{m}^{-2}\right)\end{array}$ & $\begin{array}{l}\text { Residence Time } \\
\text { (days) }\end{array}$ & $\begin{array}{l}\text { Percent Dry } \\
\text { Deposition }\end{array}$ & Mass (Tg) & $\operatorname{AOD}(0.55 \mu \mathrm{m})$ \\
\hline Sulphate $[\mathrm{S}]$ & $60.3 \pm 0.8$ & $1.0 \pm 0.0$ & $3.3 \pm 0.1$ & 12.0 & $0.5 \pm 0.0$ & $0.024 \pm 0.001$ \\
\hline Mineral dust & $8192 \pm 399$ & $88.2 \pm 7.3$ & $2.0 \pm 0.1$ & 81.9 & $45.0 \pm 3.7$ & $0.060 \pm 0.006$ \\
\hline Sea salt & N/A & $50.3 \pm 0.1$ & N/A & N/A & $25.7 \pm 0.1$ & $0.053 \pm 0.001$ \\
\hline FFBC & $5.2 \pm 0.1$ & $0.5 \pm 0.0$ & $18.1 \pm 0.1$ & 24.1 & $0.3 \pm 0.0$ & $0.003 \pm 0.000$ \\
\hline Biomass burning & $25.9 \pm 0.1$ & $1.8 \pm 0.1$ & $7.8 \pm 0.2$ & 11.8 & $0.9 \pm 0.1$ & $0.012 \pm 0.001$ \\
\hline Biogenic & N/A & $2.2 \pm 0.0$ & N/A & N/A & $1.1 \pm 0.0$ & $0.008 \pm 0.000$ \\
\hline FFOC & $12.7 \pm 0.1$ & $0.4 \pm 0.0$ & $5.2 \pm 0.1$ & 18.4 & $0.2 \pm 0.0$ & $0.002 \pm 0.000$ \\
\hline Nitrate $[\mathrm{N}]$ & $42.1 \pm 0.3$ & $0.2 \pm 0.0$ & $3.1 \pm 0.1$ & 13.4 & $0.1 \pm 0.0$ & $0.007 \pm 0.001$ \\
\hline
\end{tabular}

${ }^{\mathrm{a}}$ Standard deviations of annual means over 5 years are also shown. FFBC and FFOC stand for fossil fuel black and organic carbon, respectively. Masses are given in terms of sulphur for the sulphur cycle, carbon for carbonaceous aerosols, and nitrogen for nitrate. Sea-salt and biogenic aerosols are not transported in the model and hence have no emissions, deposition, or residence time. 

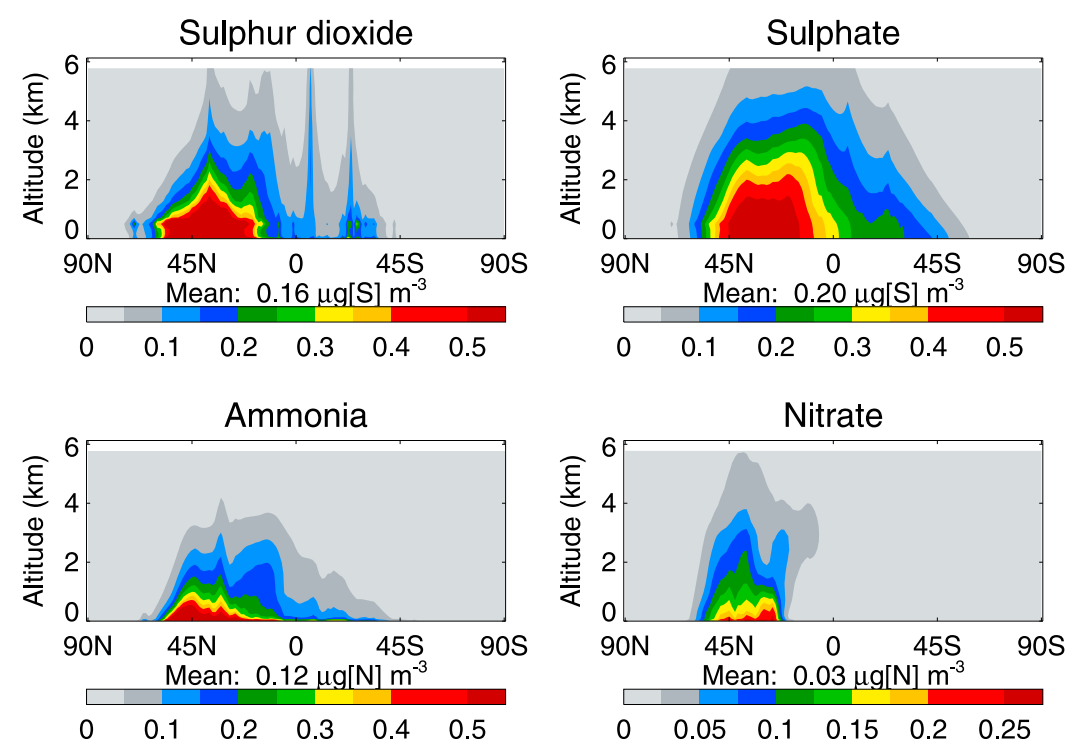

Figure 4. Vertical cross sections of zonal averaged concentrations of sulphur dioxide and sulphate aerosols (in $\mu \mathrm{g}$ [S] $\mathrm{m}^{-3}$ ) and ammonia and nitrate aerosols (in $\mu \mathrm{g}[\mathrm{N}] \mathrm{m}^{-3}$ ) in HadGEM2-ES simulation for the year 2000 .

by observations. Overestimate of bare soil fractions and underestimate of soil moisture by the interactive land surface model are the likely cause for overestimating regional mineral dust emissions. Mineral dust residence time is 2 days in HadGEM2-ES, shorter than the AeroCom-averaged residence time of 4.1 days. However, this includes all six mineral dust size divisions and the larger particle sizes are expected to deposit quickly. The residence time of the five size divisions covering 0.03 to $10 \mu \mathrm{m}$ is 4.8 days.

[20] The residence time of FFBC is long in HadGEM2-ES, at 18 days for the period 1998-2002. Since black carbon remains hydrophobic upon ageing in the model, deposition mainly occurs following diffusional impaction with cloud droplets, which is not an efficient process. Observations indicate that black carbon becomes hydrophilic with ageing, and most other aerosol numerical models include that process. The assumption made in CLASSIC is outdated and will be revised in the future. The long residence time of black carbon in the model means that this aerosol is transported over long distances, especially to the Arctic.

[21] Textor et al. [2006] do not report nitrate burden, as that species was not included in models participating in their intercomparison. Nitrate has a total mass of $0.07 \mathrm{Tg}$ [N] for the year 2000 in HadGEM2-ES. Myhre et al. [2006] have an accumulation mode nitrate mass of $0.01 \mathrm{Tg}[\mathrm{N}]$ and a mass of $0.17 \mathrm{Tg}[\mathrm{N}]$ for nitrate associated with sea salt as $\mathrm{NaNO}_{3}$. Since the HadGEM2-ES scheme does not represent the seasalt sink of nitrate, nitrate concentrations may be overestimated over oceanic regions. In addition, HadGEM2-ES does not include heterogeneous formation of coarse-mode nitrate on mineral dust particles [Usher et al., 2003], a mechanism which may be important in Asia [Li and Shao, 2009]. Adams et al. [2001], Liao et al. [2004], Rodriguez and Dabdub [2004], and Feng and Penner [2007] report global nitrate masses of $0.42,0.16,0.42$, and $0.18 \mathrm{Tg}[\mathrm{N}]$, respectively. The HadGEM2-ES nitrate mass of $0.07 \mathrm{Tg}[\mathrm{N}]$ is on the low side, highlighting the diverse results obtained from numerical models so far.
[22] Figure 4 shows vertical cross sections of zonally averaged concentrations of sulphate and nitrate aerosols and their gaseous precursors, sulphur dioxide and ammonia, as simulated for the year 2000. Results are similar to those discussed by Myhre et al. [2006]: sulphur dioxide and sulphate aerosols extend up to $5 \mathrm{~km}$ in the atmosphere, with a slow decrease in concentrations with altitude in the lower troposphere. In contrast, ammonia concentrations exhibit a strong vertical gradient which propagates to nitrate concentrations. The vertical profile of nitrate aerosols illustrates that although condensation of nitric acid to the aerosol phase is favored by lower temperatures, hence higher altitudes, the excess ammonia needed to form ammonium nitrate aerosol is located near the surface and imposes its vertical profile.

\subsection{Evolution of Sulphate and Nitrate Burdens}

[23] Figures 5 and 6 show distributions of the burden of sulphate and nitrate aerosols in 1860, 2000, and 2090 for the four RCPs. In 1860, the burden of sulphate averages $0.40 \mathrm{mg}[\mathrm{S}] \mathrm{m}^{-2}$ globally and is mainly located around major volcanoes and in the equatorial Pacific where DMS production is large. Nitrate burden is only $\left.0.02 \mathrm{mg}^{\mathrm{N}}\right] \mathrm{m}^{-2}$ on a global average in 1860 and is mainly located over India. In 2000, sulphate has increased by a factor 2.5 globally and covers large regions of the Northern Hemisphere. Nitrate burden has increased by a factor 7.5 and is predominantly located in Europe, India, and China, with smaller values seen over the United States. By 2090, the evolution of sulphate and nitrate burdens depends on the relative changes in emissions of sulphur dioxide and ammonia, and therefore on how well RCP scenarios represent future trends. Depending on the scenario, sulphate burden is 0.5 to $\left.0.7 \mathrm{mg}^{\mathrm{S}}\right] \mathrm{m}^{-2}$ on a global average in 2090 , a $30 \%-50 \%$ drop compared to 2000. The geographical distribution is dominated by natural sources, as in 1860, with India and Africa still retaining large anthropogenic burdens. In contrast, the burden of nitrate increases between 2000 and 2090 by up to a factor 2 . India and China remain associated with large nitrate burdens, 


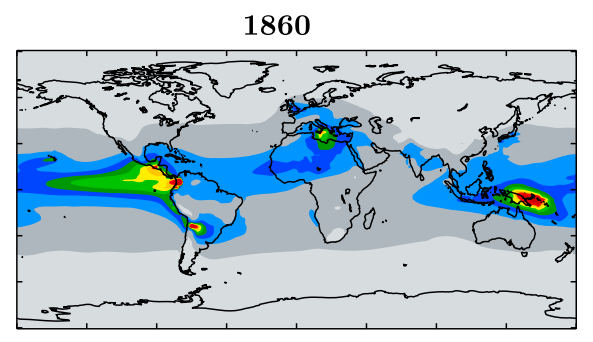

Mean: $0.40 \mathrm{mg}[\mathrm{S}] \mathrm{m}^{-2}$

2090 RCP3-PD

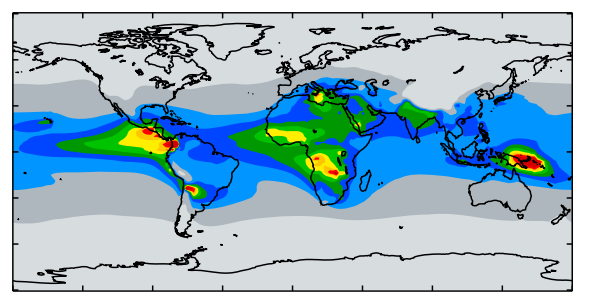

Mean: $0.51 \mathrm{mg}[\mathrm{S}] \mathrm{m}^{-2}$

2090 RCP6.0

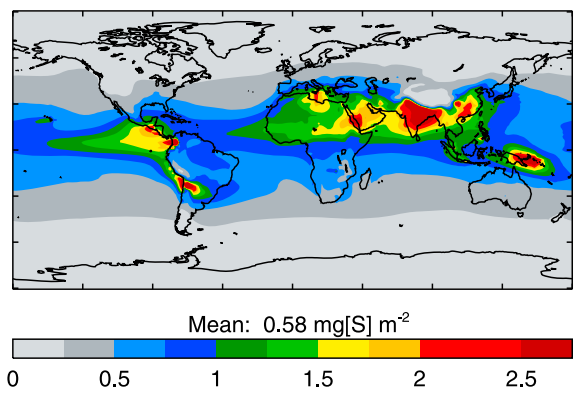

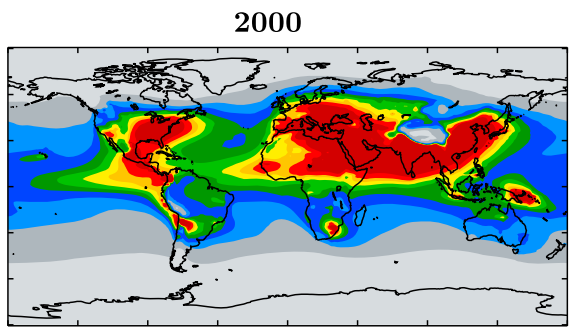

Mean: $1.01 \mathrm{mg}[\mathrm{S}] \mathrm{m}^{-2}$

2090 RCP4.5

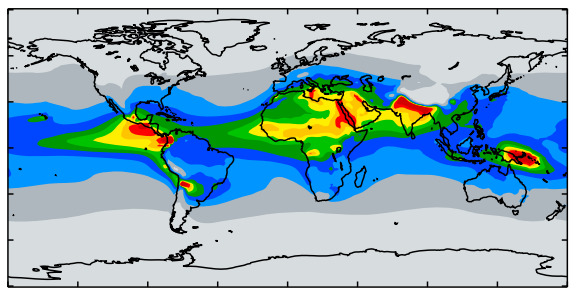

Mean: $0.60 \mathrm{mg}[\mathrm{S}] \mathrm{m}^{-2}$

2090 RCP8.5

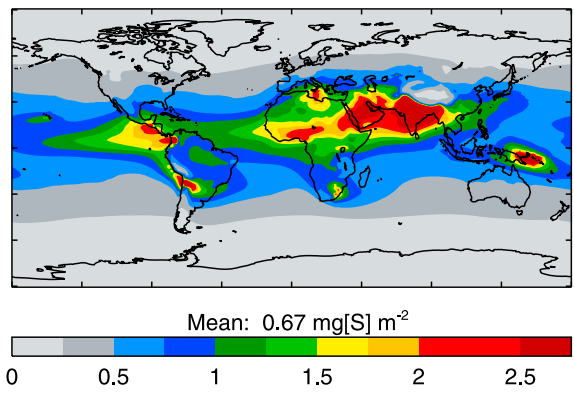

Figure 5. Five year mean distributions of sulphate aerosol burden (in $\mathrm{mg}[\mathrm{S}] \mathrm{m}^{-2}$ ) in HadGEM2-ES simulations. The 5 years are centered on the year shown on each panel.

while local maxima appear in Africa, as controlled by patterns of ammonia emissions. Although the nitrate burden has decreased in Europe and North America, it locally exceeds the sulphate burden in most scenarios.

[24] In 2090, the magnitude of nitrate burden is controlled by the relative evolution of $\mathrm{SO}_{2}$ and $\mathrm{NH}_{3}$ emissions. The largest nitrate burdens of around $\left.0.25 \mathrm{mg}^{\mathrm{N}}\right] \mathrm{m}^{-2}$ are obtained in RCP3-PD and RCP8.5. In these scenarios, $\mathrm{NH}_{3}$ emissions increase strongly while $\mathrm{SO}_{2}$ emissions decrease. In RCP6.0, where $\mathrm{NH}_{3}$ emissions level off in 2060 after a strong increase since 2010 , the burden only reaches $0.18 \mathrm{mg}$ $[\mathrm{N}] \mathrm{m}^{-2} . \mathrm{NH}_{3}$ emissions do not increase in the 21 st century according to RCP4.5, and this scenario is associated with the lowest nitrate burden in 2090 , at $\left.0.13 \mathrm{mg}^{\mathrm{N}}\right] \mathrm{m}^{-2}$.

\subsection{Evolution of Aerosol Optical Depths}

[25] Figure 7 shows time series of total and component AODs at $0.55 \mu \mathrm{m}$ in the HadGEM2-ES CMIP5 simulations. In these simulations, nitrate aerosol is not included and so its time series is not available. In the control experiment, the globally and annually averaged total AOD varies between 0.12 and 0.14 . This level corresponds to the total AOD without anthropogenic aerosol emissions or climate change. In the historical and RCP experiments, the total AOD starts diverging from the control in 1930 and increases until it peaks at 0.17 in the early 21 st century. All RCP simulations show a decline in total AOD but at different paces. By the end of the century, total AOD is back to 1950 levels. Time series of the total AOD exhibit a large year-to-year variability because of the mineral dust component.

[26] Figure 7 further shows the time series of the aerosol component AODs. The mineral dust AOD is very variable, ranging from 0.040 to 0.075 throughout the $1860-$ 2100 period. The high year-to-year variability of mineral dust also appears in satellite observations over the recent period [Allan et al., 2011]. The control simulation does show the same high variability, indicating that mineral dust in HadGEM2-ES is more responsive to internal variability as it is to climate change.

[27] Sea-salt AOD remains constant until the late 20th century, then increases by up to $12 \%$, with a maximum increase under RCP8.5. Figure 8 shows distributions of seasalt AOD, sea ice fraction, and $10 \mathrm{~m}$ wind speed as simulated for the year 2000 and changes simulated in 2090 for the four RCP experiments. Increases in sea-salt AOD occur in the Arctic and Southern Ocean and are colocated with decreased sea ice fractions and increased wind speeds. As discussed by Jones et al. [2007], retreating sea ice increases sea-salt production through two processes. First, it expands the area of open ocean available for sea-salt production. Second, it decreases surface friction, as the roughness length is $0.40 \mathrm{~mm}$ over ice and $0.05 \mathrm{~mm}$ over open water in HadGEM2-ES. A given pressure gradient will therefore produce larger near-surface wind speeds over open ocean 


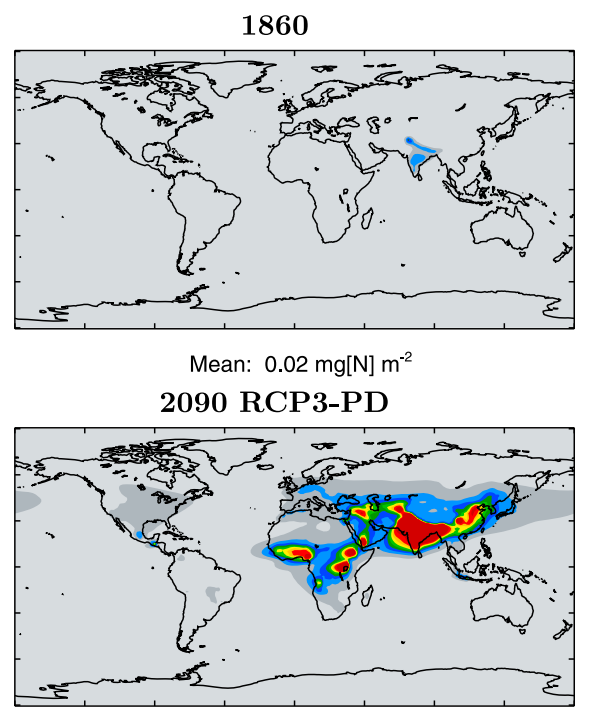

Mean: $0.25 \mathrm{mg}[\mathrm{N}] \mathrm{m}^{-2}$

2090 RCP6.0

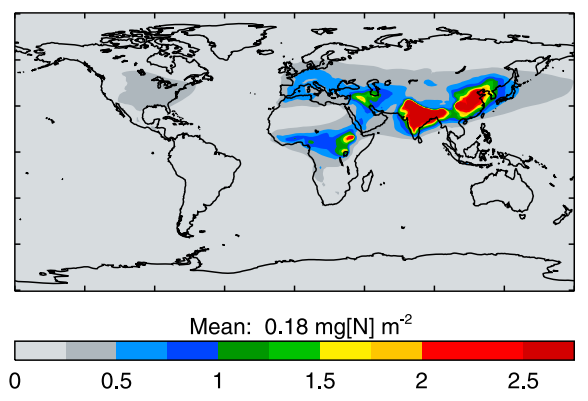

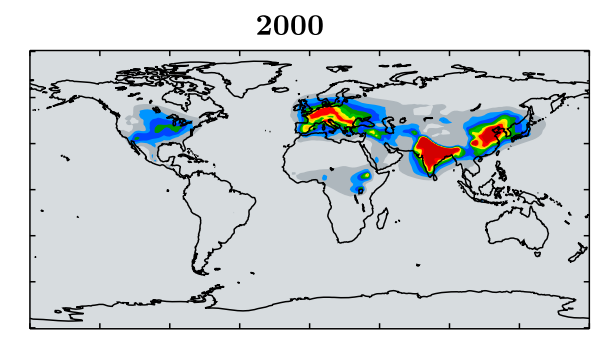

Mean: $0.15 \mathrm{mg}[\mathrm{N}] \mathrm{m}^{-2}$

2090 RCP4.5

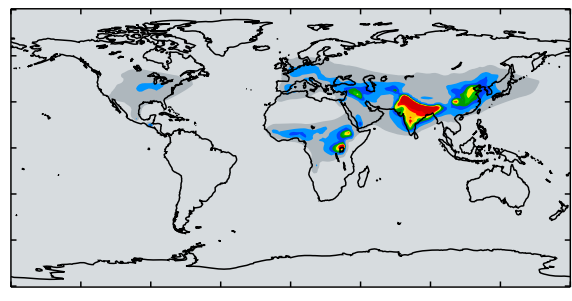

Mean: $0.13 \mathrm{mg}[\mathrm{N}] \mathrm{m}^{-2}$

2090 RCP8.5

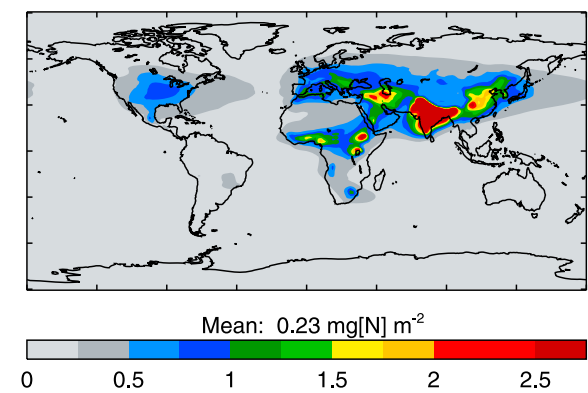

Figure 6. Five year mean distributions of nitrate aerosol burden (in $\mathrm{mg}[\mathrm{N}] \mathrm{m}^{-2}$ ) in HadGEM2-ES simulations. The 5 years are centered on the year shown on each panel.

than over sea ice, further enhancing sea-salt production. Figure 8 suggests that reductions in sea ice drive the increase in sea-salt AOD over the Arctic. Increased wind speeds are the main driver in the Southern Ocean. It is worth noting that similar increases in wind speed occurring in the Pacific Ocean do not translate into large increases in sea-salt AOD. The difference between the two regions are the initial wind speeds in 2000, which are slower by more than $5 \mathrm{~m} \mathrm{~s}^{-1}$ in the Pacific Ocean on an annual average. The parameterization of sea-salt production with wind speed is described by equations (3a)-(3f) of Jones et al. [2001]. They show that the intensification of sea-salt production with increased wind speed strongly depends on the initial distribution of wind speeds, which causes the differences seen in the two regions.

[28] Biogenic aerosol is represented in HadGEM2-ES by a fixed monthly climatology of mass mixing ratios and the corresponding AOD remains roughly constant throughout the simulated period. The very small decrease from a global average of 0.0083 to 0.0082 can be explained by a small change in the optical properties of biogenic aerosols, which respond to changes in the clear-sky mean relative humidity.

[29] Time series of sulphate and carbonaceous aerosols are more straightforward to interpret as they follow closely the time series of the corresponding precursor or primary emissions (Figure 1). Aerosol emission scenarios are therefore important and which scenario is realized in the future will strongly determine the skill of aerosol projections, and to some extent climate projections, by HadGEM2-ES. Sulphate AOD follows the bell-shaped curve of sulphur dioxide emissions, peaking over the period 1980-2020. Within that period, the geographic position of the peak moves from Europe in the 1980s to Asia in the 2020s. The remainder of the 21 st century is associated with a strong decline in sulphate AOD. Depending on the scenario, the sulphate AOD in 2100 is 0.011 to 0.016 , a $35 \%-55 \%$ drop from the peak value of 0.025 . As suggested by Rae et al. [2007], changes in the oxidizing properties of the atmosphere or in wet deposition fluxes only have a secondary impact on sulphate production, with emissions being the primary driver. For FFBC AODs, the peak occurs between 2000 and 2020 depending on the RCP, after a sixfold increase since 1860 , and is followed by a strong decrease in the 21 st century. AOD by FFBC reaches its 1860 level in 2100 under RCP3-PD. Time series of biomass burning AOD are as diverse as the emission scenarios. Depending on scenario, biomass burning AOD in 2100 is between 50\% and $100 \%$ of present-day levels. Note that because of the suppression of biomass burning sources in southeastern United States from 1900 onward, the globally averaged biomass burning AOD in the historical simulation is lower than that in the control simulation for the first 5 decades of the 20th century. The full time series of nitrate AOD is not available, but short periods have been simulated by time 

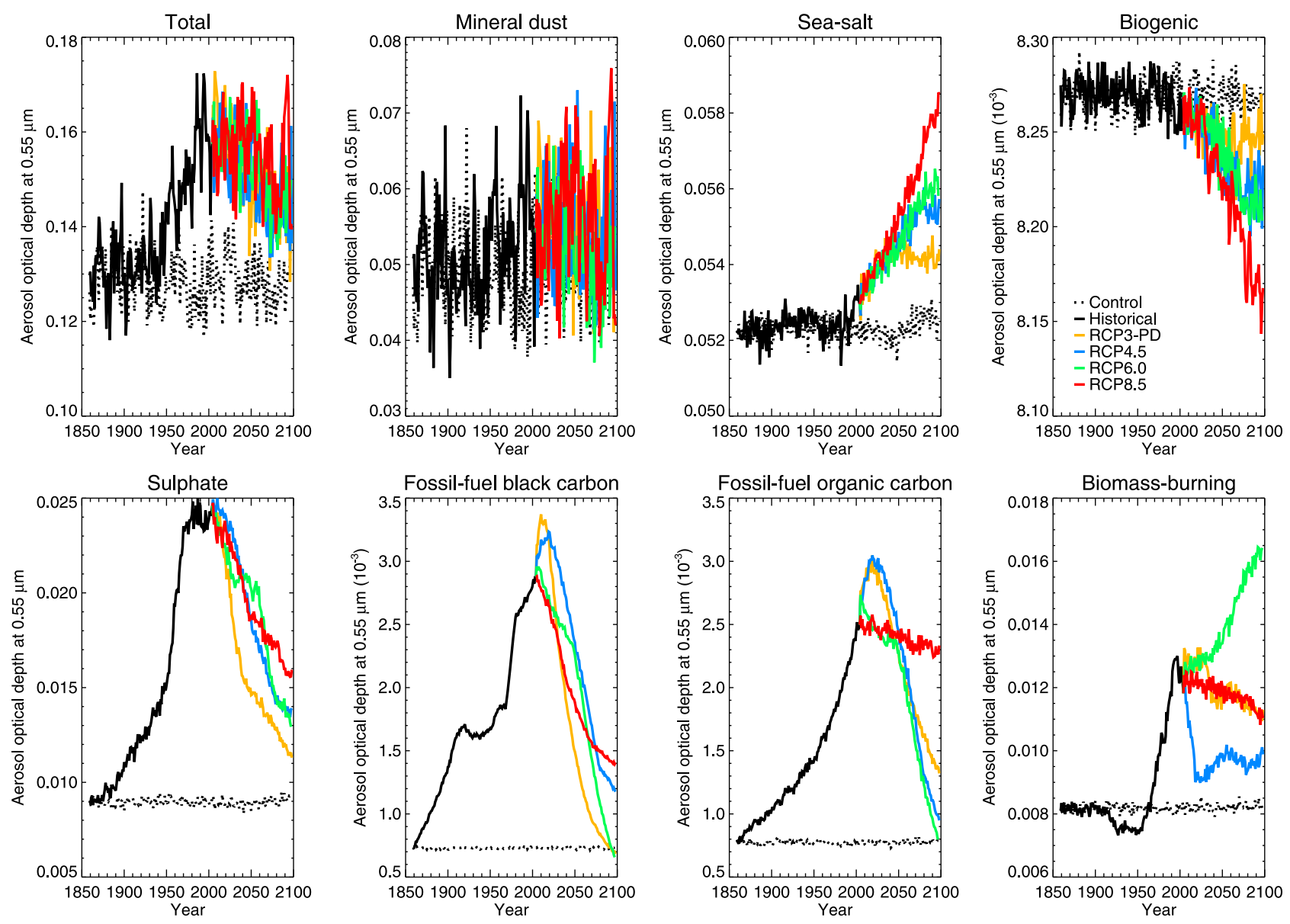

Figure 7. Time series of global and annual averaged total and component aerosol optical depth at $0.55 \mu \mathrm{m}$ in HadGEM2-ES CMIP5 simulations. The control simulation is shown as a dashed black line, the historical simulation is shown as a solid black line, and the four RCP simulations are shown in color. Note that the $\mathrm{y}$ axis scale varies for each component and has been magnified by a factor $10^{3}$ for black carbon, organic carbon, and biogenic aerosols.

slice experiments for 1860, 2000, and 2090 under the four RCPs. The globally averaged nitrate AOD at $0.55 \mu \mathrm{m}$ shows an increasing trend in the historical period, from 0.001 in 1860 to 0.007 in 2000 . Nitrate AOD thus increases from being one tenth to one quarter of sulphate AOD. The nitrate AOD follows the evolution of the nitrate burden, discussed in section 3.2, and is similarly controlled by the relative evolution of $\mathrm{SO}_{2}$ and $\mathrm{NH}_{3}$ emissions. In scenarios where $\mathrm{NH}_{3}$ emissions increase strongly while $\mathrm{SO}_{2}$ emissions decrease, namely, RCP3-PD and RCP8.5, nitrate AOD reaches its largest values at 0.010 and 0.009 , respectively, compared to sulphate AODs of 0.011 and 0.015 , respectively. In RCP6.0, where $\mathrm{NH}_{3}$ emissions level off in 2060 after a strong increase since 2010, nitrate AOD is 0.007 , half the sulphate AOD. RCP4.5 is associated with the lowest nitrate AOD in 2090, at 0.005 , with sulphate at 0.013 , because $\mathrm{NH}_{3}$ emissions do not increase in the $21 \mathrm{st}$ century according to that scenario.

[30] Emissions not only change on a global mean, but their geographic location also changes. Consequently, a change in the pattern of total AOD can be expected. Figure 9 shows 5 year mean distributions of total aerosol optical depth at $0.55 \mu \mathrm{m}$ at selected times in the HadGEM2-ES CMIP5 simulations, where nitrate aerosols are not included. In 1860, total AOD is dominated by natural aerosols, mineral dust and sea salt, with a significant biomass burning contribution in southeastern United States. This picture has changed significantly by 1950 , where North America, Europe and the North Atlantic are now associated with large optical depths. By 1980, these have increased further, especially in eastern Europe. AODs in South America and central Africa also increase with increasing biomass burning activity. In 2000, North American and European AODs have strongly decreased as the bulk of industrial emissions and the AOD they cause have moved to Asia. In 2090, simulations using different RCPs agree that the total AOD over North Hemisphere continents is low. The global pattern resembles that of the 1860 s, with mineral dust and sea salt once again dominating the total AOD distribution.

\subsection{Evolution of Aerosol Residence Times}

[31] Aerosol residence times are expected to change as the efficiency of aerosol sinks changes with atmospheric stability and precipitation rates. Figure 10 (top) shows time series of aerosol residence times for transported species, therefore excluding sea-salt and biogenic aerosols. The residence time 


\section{Sea-salt optical depth}
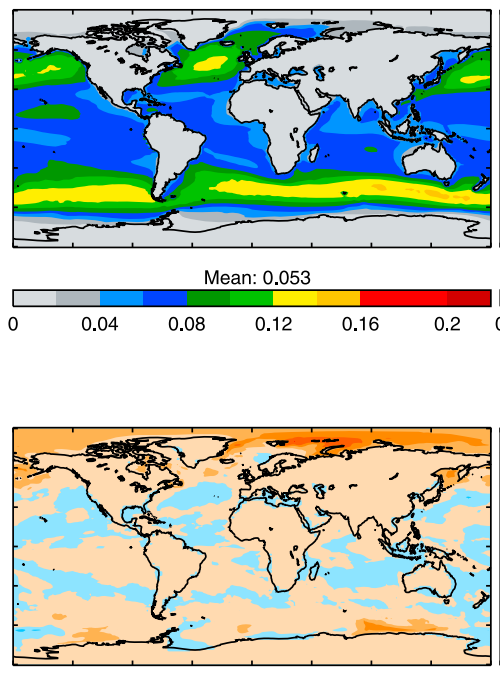

Mean: +0.001

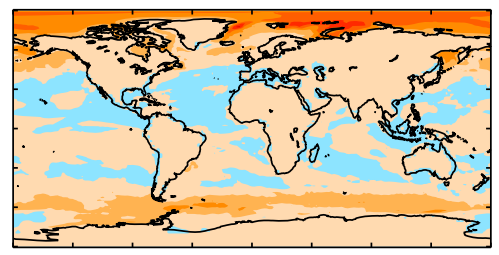

Mean: +0.002

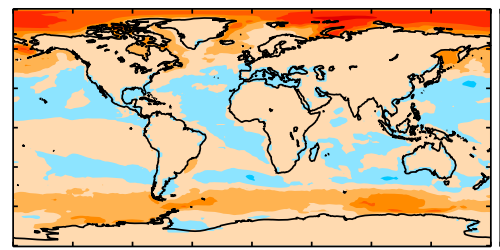

Mean: +0.003
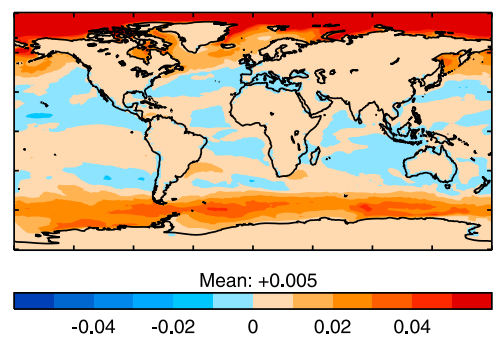

Sea-ice fraction 2000
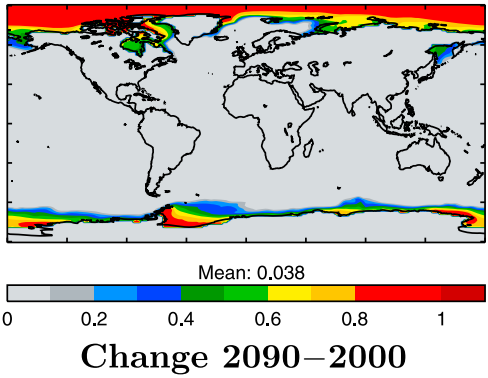

RCP 3-PD

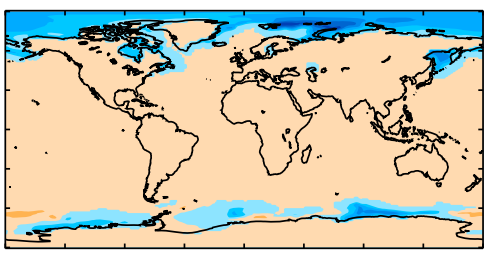

Mean: -0.008

RCP 4.5

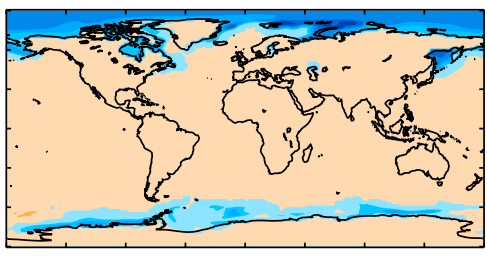

Mean: -0.011

RCP 6.0

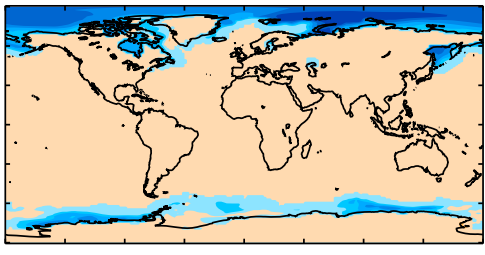

Mean: -0.014

RCP 8.5
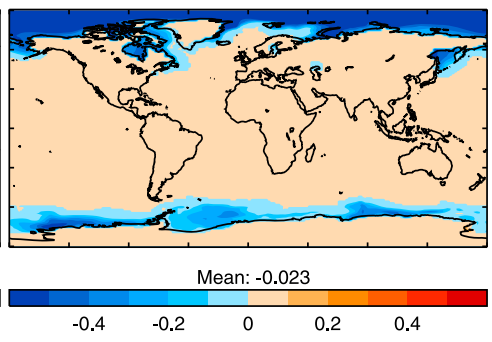

10-m wind speed
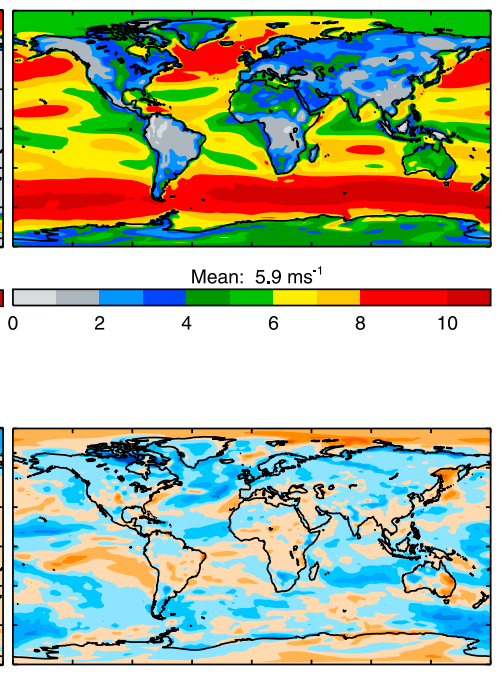

Mean: $-0.05 \mathrm{~ms}^{-1}$

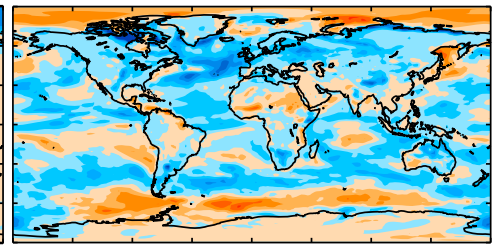

Mean: $-0.08 \mathrm{~ms}^{-1}$

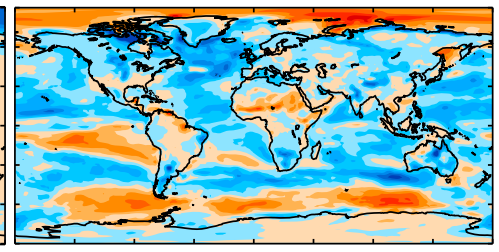

Mean: $-0.08 \mathrm{~ms}^{-1}$
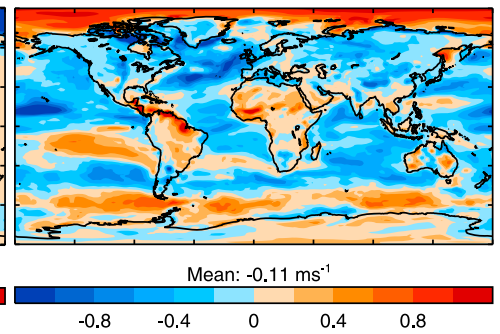

Figure 8. (left) Sea-salt optical depth at $0.55 \mu \mathrm{m}$, (middle) sea ice fraction, and (right) $10 \mathrm{~m}$ wind speed $\left(\mathrm{m} \mathrm{s}^{-1}\right)$ in HadGEM2-ES. The first row shows distributions simulated for the year 2000. The second to fifth rows show changes between 2000 and 2090 in the four RCP simulations.

of mineral dust is also not shown as it remains fairly constant throughout the 1860-2100 period in all simulations, at 1.82.0 days. Sulphate residence times start by decreasing, reaching a minimum of 3 days in the 1960 s, before increasing again to more than 4 days at the end of the 21 st century. The residence times of FFOC and biomass burning aerosols gains up to 3 days over the period 1860-2100. FFBC aerosols first experience a decrease in residence time, losing 2 days in 2000 compared to 1860 . Its residence time then increases again in the 21 st century under all scenarios, although the increase in RCP6.0 is slow. Nitrate time series are again not available but its residence time can be obtained from time slice experiments. It increases from 2.3 days in 1860 to 3.1 days in 2000. In 2090, nitrate residence time has increased again, to 4.4 days in RCP3-PD, 3.5 days in RCP4.5, 3.8 days in RCP6.0, and 4.1 days in RCP8.5. Consequently, aerosols have longer residence time in 2090 than in 2000. Considering that global warming increases the globally averaged total precipitation 
1860

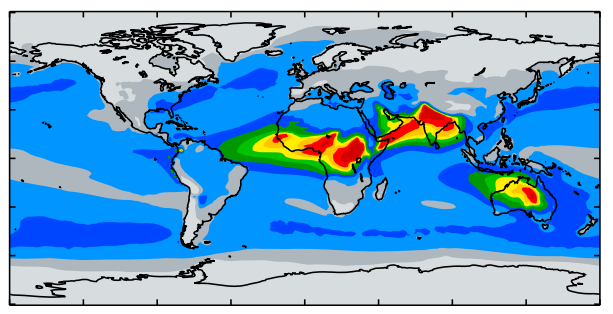

Mean: 0.127

1980

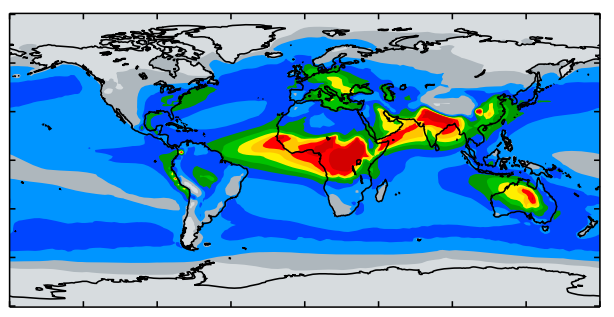

Mean: 0.149

2090 RCP3-PD

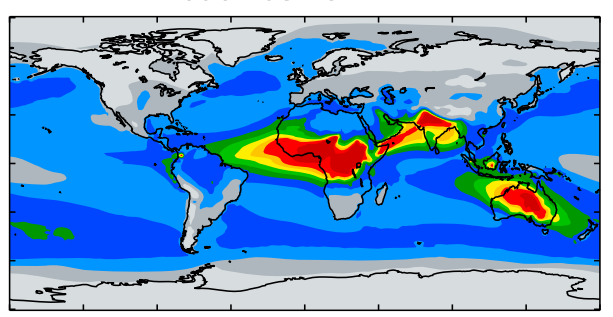

Mean: 0.147

2090 RCP6.0
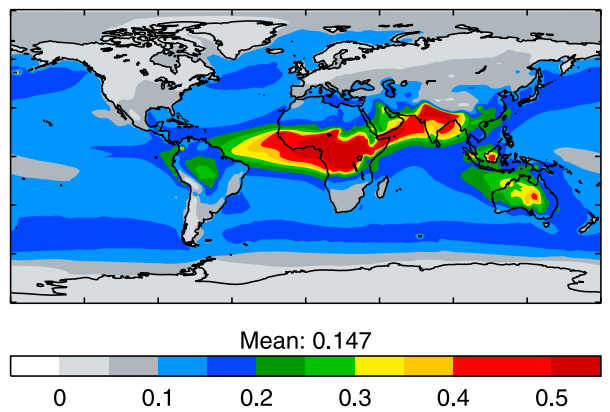

1950

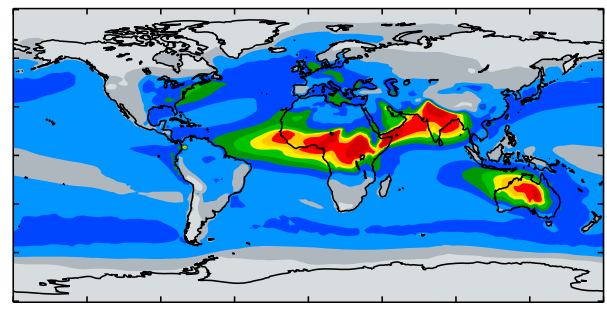

Mean: 0.139

2000

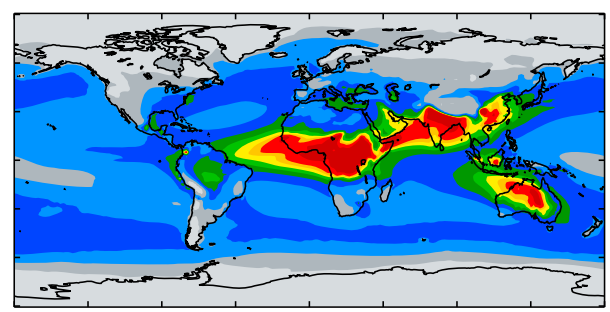

Mean: 0.158

2090 RCP4.5

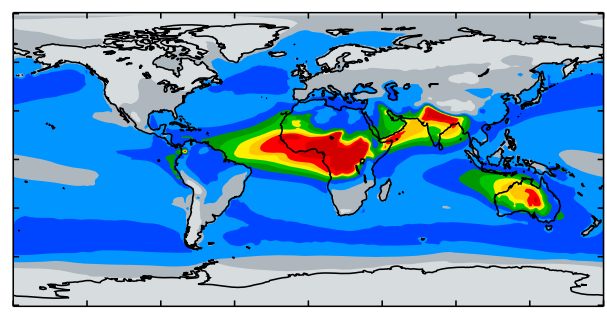

Mean: 0.142

2090 RCP8.5
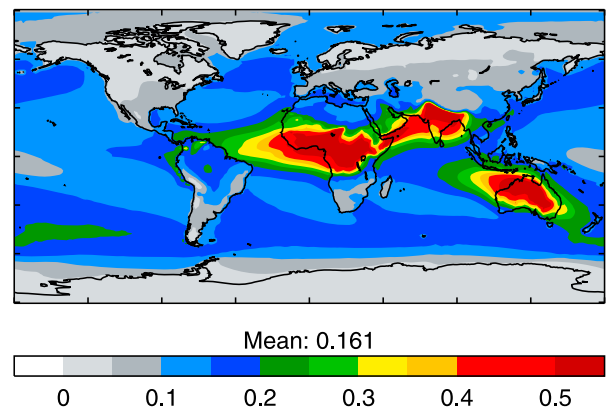

Figure 9. Five year mean distributions of total aerosol optical depth at $0.55 \mu \mathrm{m}$ in HadGEM2-ES simulations. The 5 years are centered on the year shown on each panel.

rate in HadGEM2-ES, from $3.1 \mathrm{~mm} \mathrm{~d}^{-1}$ in 2000 to $3.2-$ $3.3 \mathrm{~mm} \mathrm{~d}^{-1}$ in 2090 depending on the scenario, an increase in aerosol residence time might not be expected. Moreover, the globally averaged precipitation rate weighted by sulphate aerosol burden is $3.1 \mathrm{~mm} \mathrm{~d}^{-1}$ in 2000 and $4.0-4.2 \mathrm{~mm} \mathrm{~d}^{-1}$ in 2090 depending on scenario, suggesting that it is not the shift in the locations of sulphate aerosol and/or rainfall that is responsible for the increased residence time.

[32] Wet deposition by large-scale precipitation represents $64 \%$ of sulphate total deposition, $55 \%$ for FFOC and biomass burning aerosols, $82 \%$ for nitrate and is therefore the dominant removal process for those species. For FFBC, the dominant process is wet deposition by convective precipitation, which represents $55 \%$ of the total deposition flux. These percentages change as climate changes: typically, removal by large-scale precipitation decreases by less than $10 \%$ to the benefit of removal by convective precipitation and dry deposition. A good measure of the strength of removal by large-scale precipitation is the fraction of total aerosol mass which lies in the dissolved mode, hereafter termed dissolved fraction. In HadGEM2-ES, mass transfer to and from the dissolved mode is mostly controlled by the cloud fraction, as described in Appendix A. Time series of dissolved fraction are shown in Figure 10 (bottom). For all species except FFBC, residence time and dissolved fraction follow opposite trends: when dissolved fraction decreases, residence time increases and vice versa. For FFBC, the most efficient removal process is convective precipitation, which is unrelated to the dissolved fraction and more difficult to 

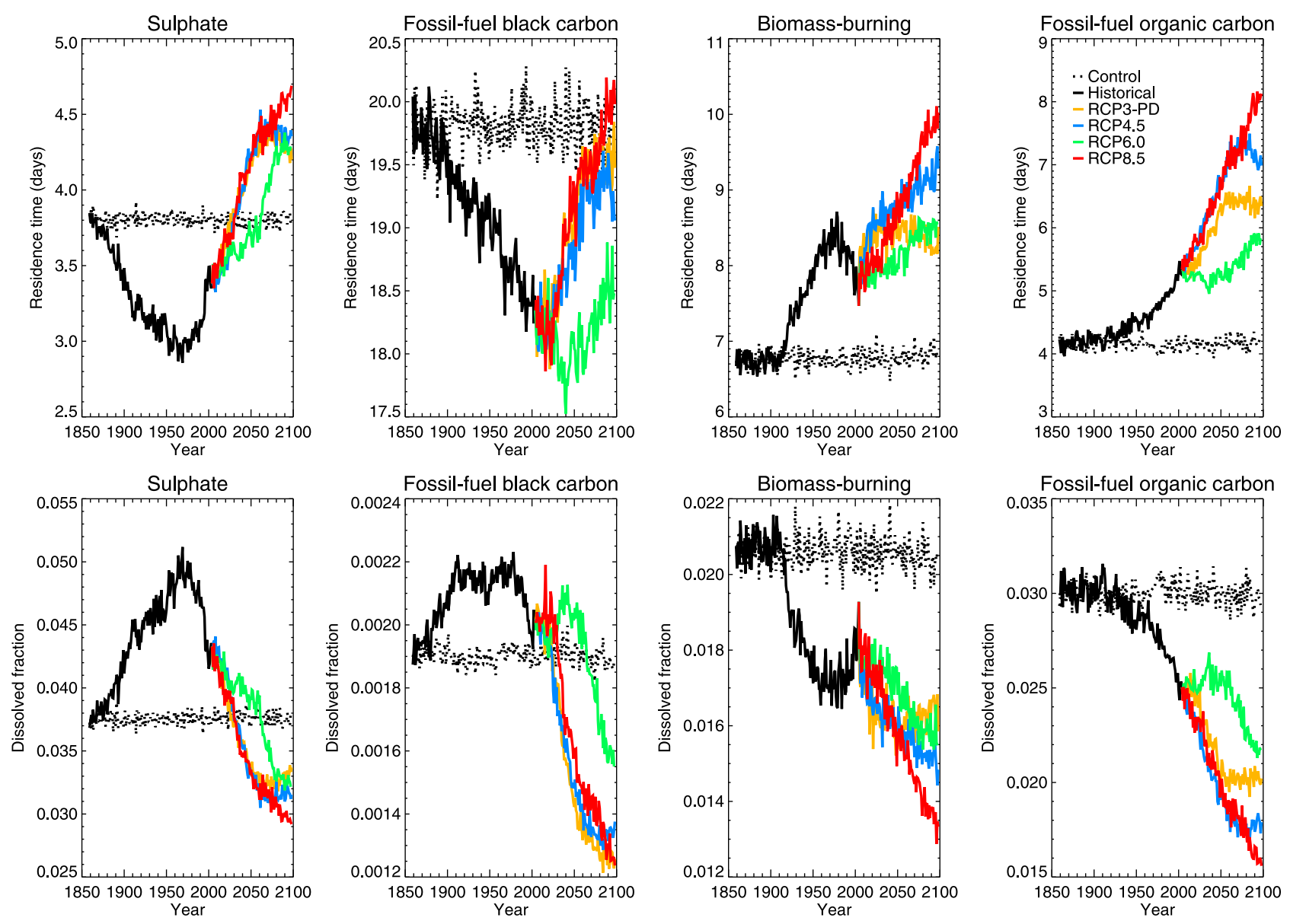

Figure 10. (top) Time series of globally and annually averaged aerosol residence times (days) for transported aerosol species in HadGEM2-ES CMIP5 simulations. (bottom) Time series of fraction of dissolved mass to total mass. Lines are as in Figure 7.

diagnose. Changes in dissolved fraction however explain part of the change in FFBC residence time.

[33] Residence times therefore increase in the 21st century because wet deposition rates by large-scale precipitation decrease. This result is opposite to that by Racherla and Adams [2006] and Liao et al. [2009], who find increased wet deposition rates. Time series of cloud cover in the CMIP5 simulations are shown in Figure 11 (top). They show a decrease in cloud cover over the 21 st century with increasing global near-surface temperatures. There are thus fewer clouds for aerosols to interact with. In addition, Figure 11 shows vertical cross sections of changes in aerosol and cloud water concentrations in time slice simulations initialized with 1860 or 2090 RCP8.5 climate. Both simulations use RCP8.5 aerosol and chemistry emissions for 2090: differences are therefore due to climate change alone. Other RCPs would show the same qualitative results but RCP8.5 maximize the effect as it is associated with the largest climate change. Cloud water concentrations decrease throughout the lowermost $7 \mathrm{~km}$ of the atmosphere between $50^{\circ} \mathrm{N}$ and $50^{\circ} \mathrm{S}$, where most aerosols are located, and increase at higher latitudes, again suggesting that aerosols and low- and middle-level clouds are less likely to be colocated in the future. As cloud feedbacks differ among climate models, especially for low clouds [Bony et al., 2006], a model that simulates an increase in low clouds with global warming should see a decrease in aerosol residence time, opposite to the result presented in this study. In HadGEM2-ES, the less efficient removal processes in a warmer world increase the aerosol concentrations throughout the troposphere, except for FFBC and nitrate. The cross section for FFBC shows decreases aloft and increases near the surface. The nitrate cross section shows a dipole pattern where concentrations increase above $5 \mathrm{~km}$ and decrease below. This is due to the temperature-dependent formation of nitrate which favors colder temperature and occurs higher in a warmer world. In addition, the oxidation of sulphur dioxide to form sulphate aerosols is also favored by climate change, at the expense of nitrate formation, as discussed in section 4 .

\section{Aerosol Radiative Forcing}

[34] Forster et al. [2007, p. 133] define radiative forcing as "the change in net irradiance at the tropopause after allowing for stratospheric temperatures to readjust to radiative equilibrium, but with surface and tropospheric temperatures and state held fixed at the unperturbed values." Here, stratospheric adjustment is neglected as tropospheric aerosols do not affect stratospheric temperatures significantly. For tropospheric aerosols in HadGEM2-ES, forcing is diagnosed by 

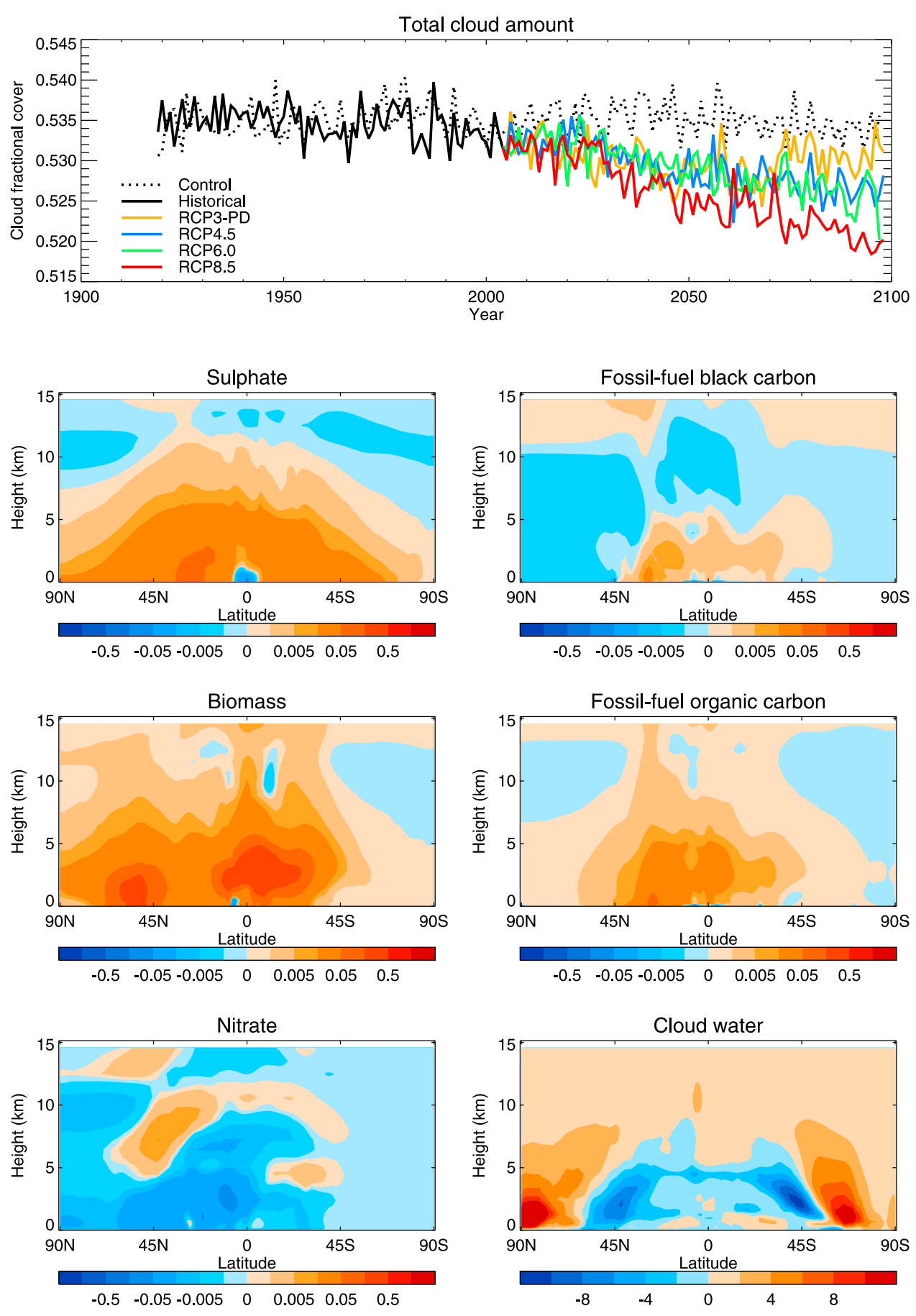

Figure 11. (top) Time series of globally and annually averaged cloud fraction in HadGEM2-ES CMIP5 simulations. Lines are as in Figure 7. (bottom) Vertical cross sections of change in aerosol concentrations $\left(\mu \mathrm{g} \mathrm{m}^{-3}\right)$ and cloud water concentration $\left(\mathrm{mg} \mathrm{m}^{-3}\right)$ in simulations with 1860 and $2090 \mathrm{RCP} 8.5$ climate sharing the same aerosol emissions. For aerosol panels, note the logarithmic color scale.

calling the radiation scheme twice, with aerosol radiative effects included in the first call and not included in the second call, which is used to advance the model into its next time step. This configuration provides the aerosol forcing with respect to an atmosphere containing no aerosols. The aerosol forcing exerted by changes in aerosol concentrations since 1860 is then obtained by taking the difference with a parallel simulation where aerosol emissions are set to rep- resent 1860. In double-call simulations, meteorology remains the same independent of the aerosols included in the simulation. As emissions of mineral dust and sea salt derive directly from the simulated meteorology, these aerosols will be the same in all double-call simulations and thus exert no radiative forcing by construction. Consequently, the change in total AOD between the simulated year and 1860 is only due to sulphate, carbonaceous, and nitrate aerosols and is 
termed anthropogenic AOD. In addition, direct and first indirect radiative forcing are the only aerosol effects that can be diagnosed in that way. Semidirect and second indirect radiative forcings imply modifications to clouds which prevents the tropospheric state from being held fixed. Quantifying those forcings uses different methods, not comparable quantitatively to the aerosol forcing as defined above [Lohmann et al., 2010]. Hereafter, aerosol radiative forcing refers to the sum of direct and first indirect effects. Finally, coupling between aerosols and chemistry represents a challenge for double-call simulations. Aerosols modify directly or indirectly the concentrations of radiatively active chemical species, such as methane and ozone. This process is not considered to be part of the aerosol forcing, yet a realistic representation of aerosols requires accounting for it. In HadGEM2-ES, this issue is resolved by using two independent sets of mass mixing ratios for methane and ozone: actual concentrations are used in the chemistry module, while the radiation scheme uses prescribed values.

[35] Double-call simulations are 5 years long and are an opportunity to add nitrate to HadGEM2-ES and investigate its role in the magnitude and evolution of aerosol forcing, by comparing simulations with and without nitrate aerosols. In order to keep the number of double-call simulations reasonably low, simulations are made for 1860, 1950, 1980, 2000 for historical emissions, and 2030 and 2090 for RCP emissions. Double-call simulations use the climate simulated for the year 1860 as suggested by the definition of radiative forcing given above. The forcing is therefore purely a function of changes in aerosol emissions and production. However, it is also interesting to look at the impact of climate change on the forcing, and results from doublecall simulations using 2090 climate are also discussed. In the following, forcing is given as the sum of both shortwave and longwave forcings. Longwave forcing remains in the range $0.01-0.08 \mathrm{~W} \mathrm{~m}^{-2}$, with smaller values found at the top of the atmosphere (TOA) in all-sky conditions and larger values at the surface in clear-sky, or cloud-free, conditions. Consequently, the shortwave forcing dominates the net signal.

\subsection{Forcing Diagnosed With Respect to 1860 Climate}

[36] Figure 12 shows distributions of anthropogenic AOD, as defined above, and all-sky direct and first indirect aerosol forcing at the TOA in 2000 and 2090 for RCP4.5 relative to 1860 , with and without nitrate, and differences due to nitrate. All RCPs share similar forcing patterns in 2090. In 2000, the anthropogenic AOD is large over Western industrialized countries, Asia, and biomass burning regions of Africa and South America. Regions where biomass burning emissions are larger in 1860 than 2000 appear as regions of negative anthropogenic AODs, such as the southeastern United States and small areas in South America. Nitrate contributes 23\% of the anthropogenic AOD in 2000 and is located in Europe, India, China, and central United States, in agreement with the distribution of nitrate burden shown in Figure 6. Aerosol forcing follows the distribution of the anthropogenic AOD but is also strong over ocean as maritime clouds are more susceptible to the first indirect effect than continental clouds. In 2090, anthropogenic AOD is much reduced, with large positive values in central Africa only, and negative values over a large fraction of the Northern Hemisphere and South
America in simulations without nitrate aerosols. Negative values correspond to areas where aerosol burden is larger in 1860 than in 2090 because of extreme reductions in most aerosol and aerosol precursor emissions between those two years. As a consequence, aerosol forcing is weak in 2090. The addition of nitrate adds optical depth in 2090 and this species now represents $56 \%$ of the anthropogenic AOD. Nitrate switches the forcing back to negative values, except where biomass burning aerosols used to dominate 1860 concentrations such as in the Southeastern United States.

[37] Time series of globally averaged anthropogenic AOD and TOA forcing are shown in Figure 13 for all-sky and clear-sky conditions, with and without nitrate. The impact of nitrate aerosols is made clearer by also showing ratios of nitrate to no-nitrate values. The main features of these time series are the peak values achieved in 2000-2030, and the impact of nitrate which maintains the aerosol forcing at stronger values throughout the 21 st century. Without nitrate in 2000, the all-sky direct forcing is $-0.16 \pm 0.01 \mathrm{~W} \mathrm{~m}^{-2}$ and total forcing (direct and first indirect) is $-1.45 \pm 0.03 \mathrm{~W} \mathrm{~m}^{-2}$. Including nitrate makes those forcings stronger, at $-0.28 \pm$ 0.01 and $-1.62 \pm 0.03 \mathrm{~W} \mathrm{~m}^{-2}$, respectively. Numbers following plus and minus signs measure the year-to-year variability within 5 year simulations and reflect the small changes in forcing due to yearly variations in aerosols and clouds. Both direct forcing estimates are within the large range of $-0.50 \pm 0.40 \mathrm{~W} \mathrm{~m}^{-2}$ given by the Fourth Assessment Report of the IPCC [Forster et al., 2007]. Estimates including nitrate come closer to observationally based estimates [Bellouin et al., 2008], which have always included nitrate aerosols implicitly since they use total aerosol retrievals. The first indirect forcing in HadGEM2-ES, which can be diagnosed to the first order as the difference between total and direct forcing, is $-1.3 \mathrm{~W} \mathrm{~m}^{-2}$. This value is outside the $90 \%$ confidence range of -1.1 to $+0.4 \mathrm{~W} \mathrm{~m}^{-2}$ reported by Forster et al. [2007]. The first indirect effect parameterization used in HadGEM2-ES [Jones et al., 2001] might overestimate that effect by considering aerosols as externally mixed, whereas aerosols are internally mixed to some extent. By comparing with satellite retrievals, Quaas et al. [2009] suggest that HadGEM2 is among the climate models that overestimate the increase in cloud droplet number concentration with aerosol optical depth and would therefore simulate too strong a first indirect effect.

[38] The results above suggest that nitrate contributes $-0.12 \mathrm{~W} \mathrm{~m}^{-2}$ to the aerosol direct forcing in 2000. This estimate is in the middle of the range 0 to $-0.2 \mathrm{~W} \mathrm{~m}^{-2}$ obtained by previous studies cited in the introduction. It also corresponds well to the evaluation of $-0.10 \pm 0.10 \mathrm{~W} \mathrm{~m}^{-2}$ made by Forster et al. [2007]. Including the first indirect forcing, nitrate contributes $-0.17 \mathrm{~W} \mathrm{~m}^{-2}$ to the present-day aerosol forcing. Nitrate appears to have had a relatively small impact in the 20th century, enhancing the anthropogenic AOD and aerosol forcing by less than $20 \%$ in 1950 , 1980, and 2000. Without nitrate, the rate of increase in anthropogenic AOD is 0.003 per decade between 1950 and 2000. Adding nitrate increases that rate by a third to 0.004 per decade. The rate of decrease in anthropogenic AOD between 2000 and 2090 is 0.004 per decade. Adding nitrate does not modify that rate but makes the decrease start from a higher level. 
Anthropogenic aerosol optical depth: Year 2000

\section{Without nitrate With nitrate Difference}
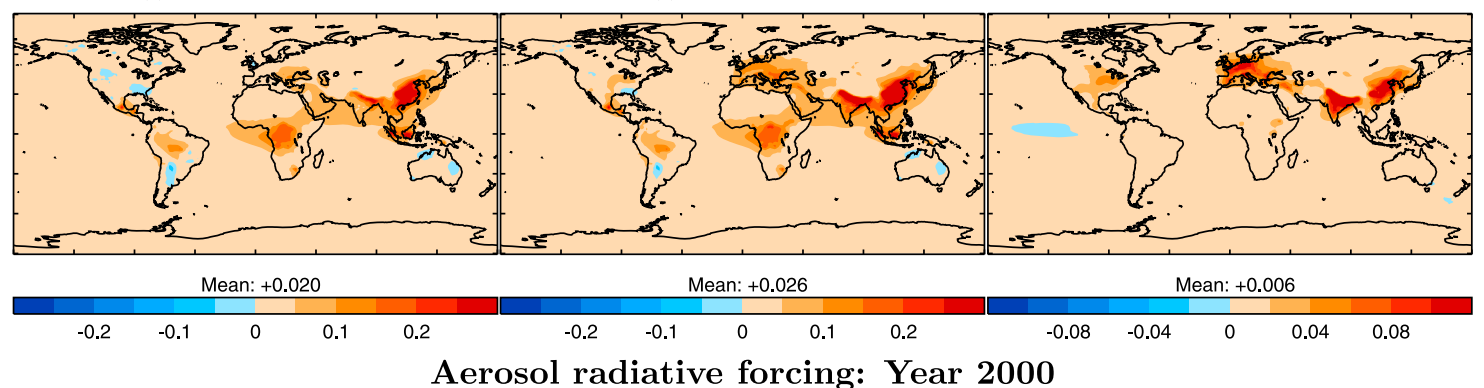

Aerosol radiative forcing: Year 2000

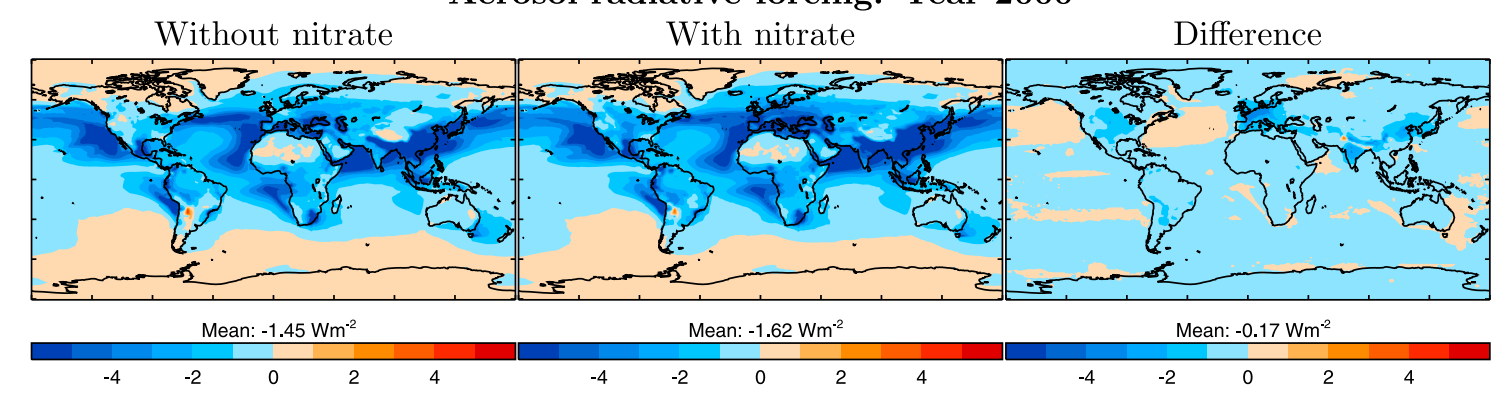

Anthropogenic aerosol optical depth: Year 2090 RCP4.5

Without nitrate

With nitrate

Difference

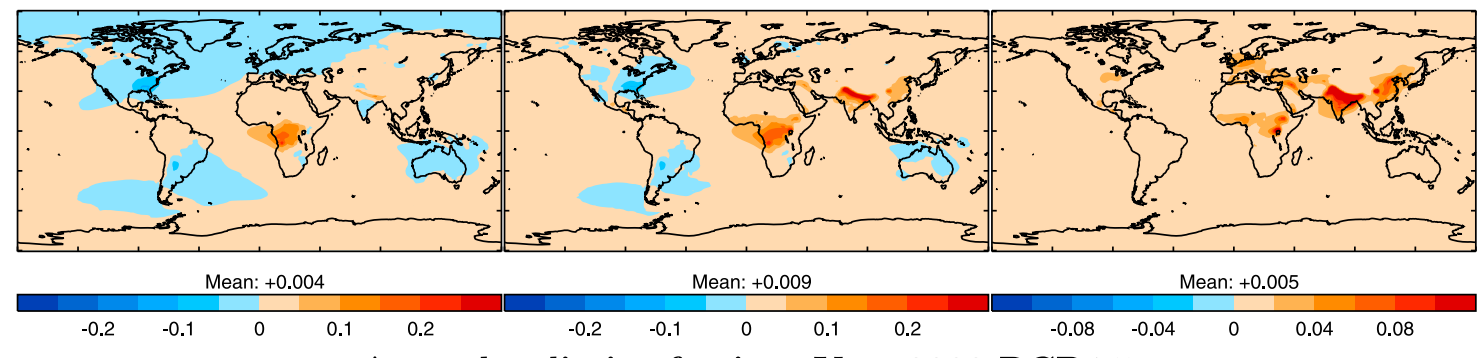

Aerosol radiative forcing: Year $2090 \mathrm{RCP} 4.5$

Without nitrate With nitrate

Difference

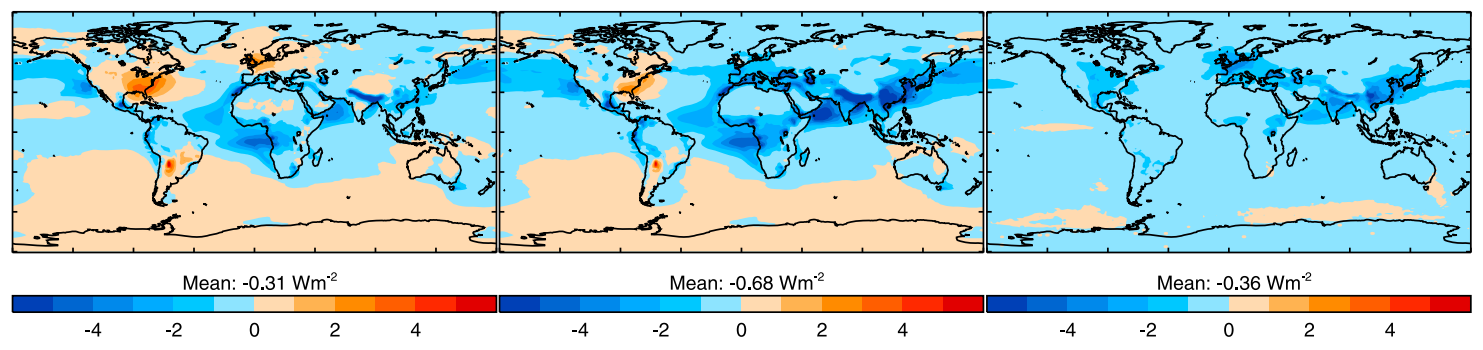

Figure 12. Anthropogenic aerosol optical depth at $0.55 \mu \mathrm{m}$ and direct and first indirect aerosol forcing with respect to 1860 in all-sky conditions at the top of the atmosphere in HadGEM2-ES CMIP5 simulations for 2000 (first and second rows) and 2090 RCP4.5 (third and fourth rows), with nitrate aerosols (left) excluded or (middle) included and (right) their difference. Forcings are in $\mathrm{W} \mathrm{m}^{-2}$ and cover shortwave and longwave spectra.

[39] As stated above, nitrate forcing is close to $-0.2 \mathrm{~W} \mathrm{~m}^{-2}$ in 2000. By 2090, it has increased to $-0.6,-0.4,-0.5$, and $-0.7 \mathrm{~W} \mathrm{~m}^{-2}$ for RCP3-PD, RCP4.5, RCP6.0, and RCP8.5, respectively, making it the single most important aerosol forcing agent of that time. Variations in the impact of nitrate between RCPs stem from aerosol emission time series. Nitrate has the largest impact in RCP3-PD because this scenario yields the largest decrease in $\mathrm{SO}_{2}$ emissions with a strong increase in $\mathrm{NH}_{3}$ emissions. RCP8.5 comes next as it provides the strongest increase in $\mathrm{NH}_{3}$ emissions with a strong decrease in $\mathrm{SO}_{2}$ emissions. This scenario yields the largest nitrate AOD in 2090 at 0.011 , and consequently has the largest nitrate impact on clear-sky aerosol forcing. RCP4.5 has the smallest anthropogenic AOD in 2090 of all scenarios because of the large decrease in biomass burning emissions. The impact of nitrate is limited as $\mathrm{NH}_{3}$ emissions remain flat. Finally, RCP6.0 is associated with the weakest impact of nitrate on anthropogenic AOD and aerosol forcings. Nitrate remains an important species in that scenario however, since $\mathrm{NH}_{3}$ emissions increase and $\mathrm{SO}_{2}$ emissions 

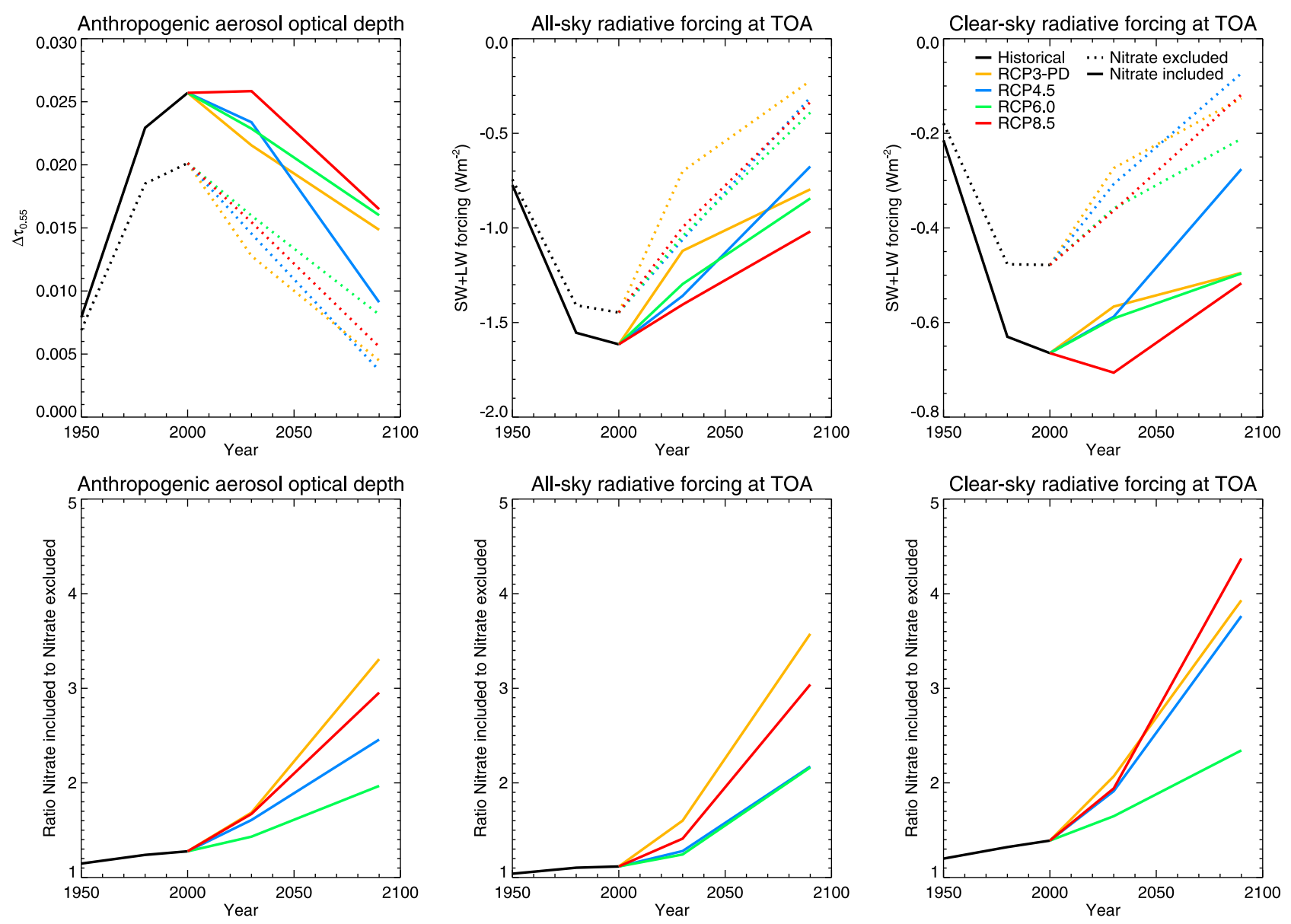

Figure 13. (top) Anthropogenic aerosol optical depth at $0.55 \mu \mathrm{m}$ and aerosol radiative forcing at the top of the atmosphere in HadGEM2-ES CMIP5 simulations. Solid lines include nitrate aerosols, and dashed lines do not. Aerosol forcing is the sum of direct and first indirect forcings in shortwave and longwave spectra. (bottom) Nitrate to no-nitrate ratio in corresponding plots in Figure 13 (top).

decrease, but its impact is shadowed by the large increase in biomass burning emissions in RCP6.0. As a summary, Figure 13 (bottom) shows the ratio of anthropogenic AOD and radiative forcing when nitrate is included to when it is excluded. By 2090 nitrate accounts for $50 \%-70 \%$ of the anthropogenic AOD and the radiative forcing depending on the RCP. This clearly demonstrates the importance of including nitrate in future simulations of climate change.

[40] At the surface, the aerosol forcing is typically greater in absolute magnitude than at the TOA, since increases in both aerosol scattering and absorption act to decrease downward shortwave fluxes. Aerosol forcing at the surface is a contributor to the global dimming and brightening phenomenon, whereby the amount of solar radiation reaching the surface has decreased between 1950 and 1980 before recovering partially [Wild, 2009]. Other contributors are changes in cloud properties and cover, which are in part related to aerosol indirect effects, and changes in gases absorbing in the shortwave, especially water vapor. Time series of aerosol forcing at the surface are shown in Figure 14 and exhibit the same profile as the aerosol forcing at TOA shown in Figure 13: stronger forcing in the early 21 st century followed by a decrease mitigated by the addition of nitrate aerosols. The impact of nitrate at TOA and surface is comparable, making the surface forcing stronger by a factor 2 to 3 depending on the scenario.

\subsection{Forcing Diagnosed With Respect to 2090 Climate}

[41] Aerosol forcing as computed above gives the perturbation of radiative fluxes to which the climate system responds. It is only due to changes in aerosol primary and precursor emissions. It does not measure the contribution of aerosols to changes in radiative fluxes, as climate change also impacts aerosols by modifying their residence time and chemical oxidants. To assess this impact, 5 year double-call simulations are performed for each RCP starting with a 2090 climate, using 1860 or 2090 aerosol and chemistry emissions, with and without nitrate. Since results are qualitatively similar in all RCPs, Table 2 shows results for RCP8.5 only. Without nitrate, anthropogenic AOD increases by $14 \%$ when 2090 climate is used, without much impact on aerosol forcing. With nitrate, anthropogenic AOD decreases by $6 \%$ and aerosol forcing decreases by $20 \%$. Furthermore, in simulations including nitrate, the composition of anthropogenic AOD changes significantly. Using an 1860 climate, sulphate represents $20 \%$ of the 2090 anthropogenic AOD and nitrate represents $67 \%$. Using a 2090 climate, the values are $27 \%$ and $58 \%$, respectively: nitrate aerosols have decreased while 

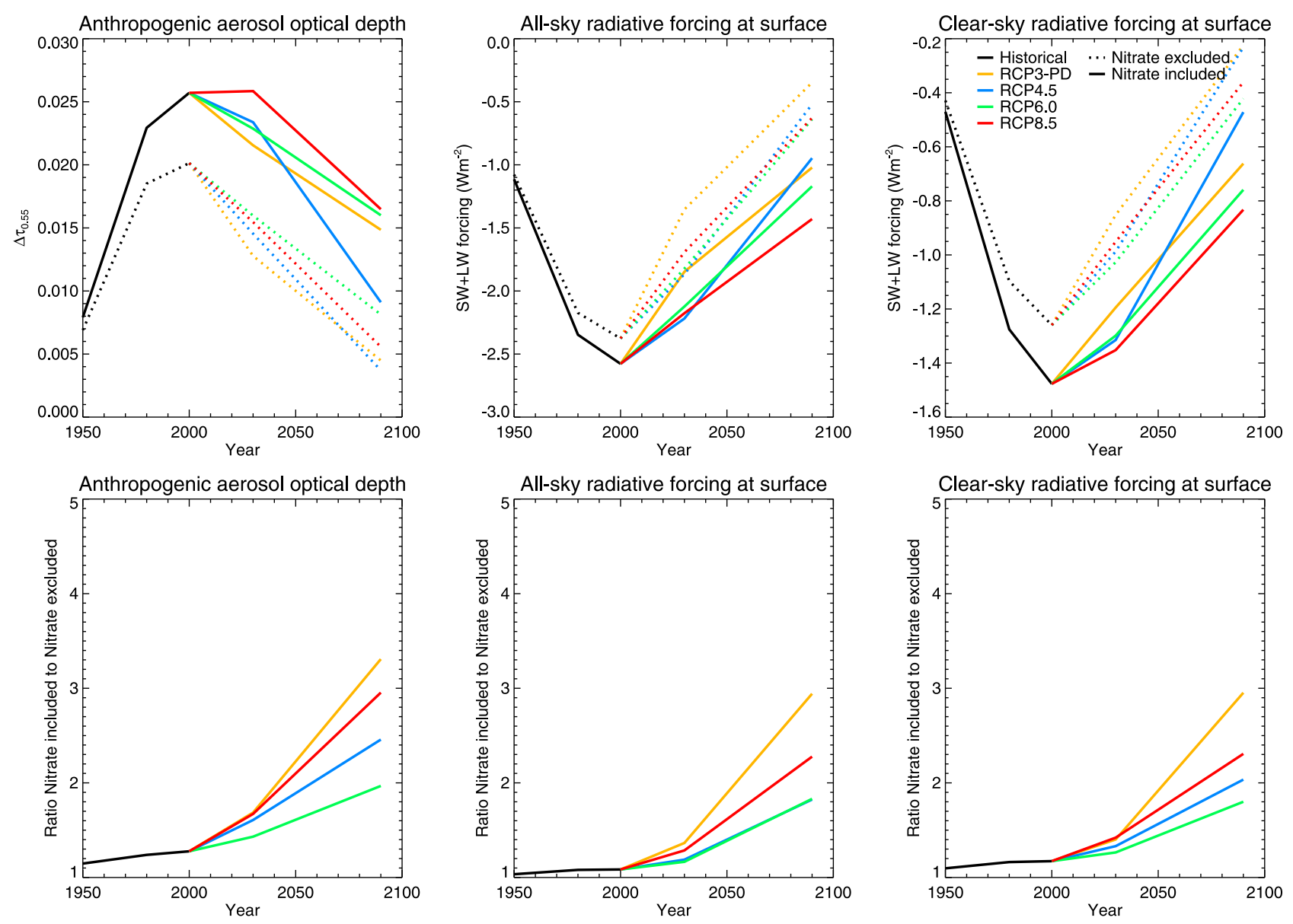

Figure 14. As in Figure 13 but for aerosol forcing at the surface.

sulphate aerosols have increased. Since nitrate aerosols are more optically efficient than sulphate aerosols (see extinction coefficients in Table A1), moving mass from nitrate to sulphate results in decreased direct forcing and the $20 \%$ drop in aerosol forcing shown in Table 2.

[42] The effect of climate change on aerosols is investigated further by fixing aerosol and chemistry emissions at 2090 levels in simulations initialized from either a 1860 or 2090 climate: all changes are then due to climate change alone. Globally and annually averaged aerosol burdens in those 5 year simulations are shown in Table 3. Carbonaceous aerosols do not depend on atmospheric chemistry in HadGEM2-ES and are analyzed first. Their burdens increase in all scenarios, with larger increases as global temperature increases more. The burden of the fossil fuel component increases by $3 \%-12 \%$, and the biomass burning component increases by $8 \%-27 \%$. The increase in aerosol residence time discussed in section 3.4 explains those increases in burden induced by climate change. Sulphate aerosol burden increases in the same fashion, by $6 \%-22 \%$. Residence time is only one cause for that increase: changes in atmospheric chemistry also impact sulphate aerosols. This is particularly apparent when looking at nitrate aerosols. In contrast to the other species, nitrate aerosol burdens are decreasing with increasing globally averaged temperature, by up to $20 \%$.
These changes must be caused by changes in atmospheric chemistry.

[43] In HadGEM2-ES the competition between sulphate and nitrate stems from the amount of oxidation experienced by $\mathrm{SO}_{2}$. When $\mathrm{SO}_{2}$ is oxidized into sulphate efficiently, the latter depletes $\mathrm{NH}_{3}$ when forming ammonium sulphate and prevents ammonium nitrate from being formed. Figure 15 shows CMIP5 time series of burdens of chemical species involved in the oxidation of $\mathrm{SO}_{2}$ in HadGEM2-ES. Note that changes in oxidant burdens are not driven by aerosol formation, as it only represents a small sink. For example, the low burdens of the hydroxyl radical $(\mathrm{OH})$ experienced during

Table 2. Change in Anthropogenic Aerosol Optical Depth $(\triangle \mathrm{AAOD})$ at $0.55 \mu \mathrm{m}$ and All-Sky Shortwave and Longwave Direct and First Indirect Aerosol Forcing at the Top of the Atmosphere $\Delta \mathrm{F}$ in 2090 Under RCP8.5, With and Without Nitrate Aerosols $^{\mathrm{a}}$

\begin{tabular}{lccccc}
\hline & \multicolumn{2}{c}{$\Delta \mathrm{AAOD}$} & & \multicolumn{2}{c}{$\Delta \mathrm{F}\left(\mathrm{W} \mathrm{m}^{-2}\right)$} \\
\cline { 2 - 3 } \cline { 5 - 6 } RCP8.5 2090 & $\mathrm{PI}$ & $\mathrm{CC}$ & & PI & $\mathrm{CC}$ \\
\hline Without nitrate & +0.006 & +0.007 & & -0.34 & -0.32 \\
With nitrate & +0.017 & +0.016 & & -1.03 & -0.83 \\
Ratio $^{\mathrm{b}}$ & 2.83 & 2.29 & & 3.03 & 2.60
\end{tabular}

${ }^{\text {a}} \mathrm{PI}$ and $\mathrm{CC}$ show results for an 1860 and 2090 climate, respectively. 
Table 3. Global, Annual Averaged Burden of Sulphate, Fossil Fuel Black and Organic Carbon, Biomass Burning, and Nitrate Aerosols and Sulphur Cycle Oxidants $\mathrm{OH}, \mathrm{HO}_{2}$, Tropospheric $\mathrm{O}_{3}$, and $\mathrm{H}_{2} \mathrm{O}_{2}$ Using CMIP5 Aerosol and Chemistry Emissions for 2090 in a 1860 (PI) or 2090 (CC) Climate

\begin{tabular}{|c|c|c|c|c|c|c|}
\hline \multirow[b]{2}{*}{$\mathrm{RCP}$} & \multicolumn{3}{|c|}{ Sulphate (mg $\left.[\mathrm{S}] \mathrm{m}^{-2}\right)$} & \multicolumn{3}{|c|}{$\mathrm{OH}\left(\mathrm{mg} \mathrm{m}^{-2}\right)$} \\
\hline & PI & $\mathrm{CC}$ & Percentage Change & PI & $\mathrm{CC}$ & Percentage Change \\
\hline RCP3-PD & 0.48 & 0.51 & $+6.0 \%$ & $3.65 \times 10^{-3}$ & $3.71 \times 10^{-3}$ & $+1.6 \%$ \\
\hline $\mathrm{RCP} 4.5$ & 0.54 & 0.60 & $+12.8 \%$ & $3.66 \times 10^{-3}$ & $3.69 \times 10^{-3}$ & $+0.9 \%$ \\
\hline RCP6.0 & 0.51 & 0.58 & $+15.5 \%$ & $3.62 \times 10^{-3}$ & $3.61 \times 10^{-3}$ & $-0.3 \%$ \\
\hline \multirow[t]{2}{*}{ RCP8.5 } & 0.55 & 0.67 & $+22.1 \%$ & $3.65 \times 10^{-3}$ & $3.56 \times 10^{-3}$ & $-2.5 \%$ \\
\hline & \multicolumn{3}{|c|}{ FFBC and FFOC $\left(\mathrm{mg}[\mathrm{C}] \mathrm{m}^{-2}\right)$} & \multicolumn{3}{|c|}{$\mathrm{HO}_{2}\left(\mathrm{mg} \mathrm{m}^{-2}\right)$} \\
\hline $\mathrm{RCP}$ & PI & $\mathrm{CC}$ & Percentage Change & PI & $\mathrm{CC}$ & Percentage Change \\
\hline RCP3-PD & 0.30 & 0.31 & $+3.3 \%$ & $3.58 \times 10^{-2}$ & $3.74 \times 10^{-2}$ & $+4.5 \%$ \\
\hline $\mathrm{RCP} 4.5$ & 0.32 & 0.34 & $+4.7 \%$ & $3.67 \times 10^{-2}$ & $3.96 \times 10^{-2}$ & $+7.9 \%$ \\
\hline RCP6.0 & 0.22 & 0.24 & $+7.7 \%$ & $3.93 \times 10^{-2}$ & $4.29 \times 10^{-2}$ & $+9.0 \%$ \\
\hline \multirow[t]{2}{*}{$\mathrm{RCP} 8.5$} & 0.48 & 0.54 & $+11.6 \%$ & $4.51 \times 10^{-2}$ & $5.26 \times 10^{-2}$ & $+16.6 \%$ \\
\hline & \multicolumn{3}{|c|}{ Biomass Burning (mg $[\mathrm{C}] \mathrm{m}^{-2}$ ) } & \multicolumn{3}{|c|}{ Tropospheric $\mathrm{O}_{3}\left(\mathrm{mg} \mathrm{m}^{-2}\right)$} \\
\hline $\mathrm{RCP}$ & PI & $\mathrm{CC}$ & Percentage Change & PI & $\mathrm{CC}$ & Percentage Change \\
\hline RCP3-PD & 1.46 & 1.56 & $+7.6 \%$ & 469.47 & 483.34 & $+3.0 \%$ \\
\hline $\mathrm{RCP} 4.5$ & 1.17 & 1.35 & $+14.6 \%$ & 517.09 & 537.35 & $+3.9 \%$ \\
\hline RCP6.0 & 1.95 & 2.28 & $+16.8 \%$ & 513.00 & 536.46 & $+4.6 \%$ \\
\hline \multirow[t]{2}{*}{$\mathrm{RCP} 8.5$} & 1.25 & 1.58 & $+26.6 \%$ & 631.27 & 659.27 & $+4.4 \%$ \\
\hline & \multicolumn{3}{|c|}{ Nitrate $\left(\mathrm{mg}[\mathrm{N}] \mathrm{m}^{-2}\right)$} & \multicolumn{3}{|c|}{$\mathrm{H}_{2} \mathrm{O}_{2}\left(\mathrm{mg} \mathrm{m}^{-2}\right)$} \\
\hline $\mathrm{RCP}$ & PI & $\mathrm{CC}$ & Percentage Change & PI & $\mathrm{CC}$ & Percentage Change \\
\hline RCP3-PD & 0.28 & 0.25 & $-11.0 \%$ & 3.32 & 3.58 & $+7.8 \%$ \\
\hline RCP4.5 & 0.16 & 0.13 & $-15.4 \%$ & 3.47 & 3.95 & $+13.8 \%$ \\
\hline RCP6.0 & 0.22 & 0.18 & $-17.3 \%$ & 4.04 & 4.65 & $+15.1 \%$ \\
\hline RCP8.5 & 0.30 & 0.23 & $-21.1 \%$ & 5.28 & 6.83 & $+29.4 \%$ \\
\hline
\end{tabular}

1950-2030 are due to reactions with methane and carbon monoxide, rather than depletion by aerosols. As oxidant burdens are larger in 2090 than in 1860, it would seem at first that $\mathrm{SO}_{2}$ has more potential to be oxidized in 2090 than in 1860 , thus explaining the preferential formation of sulphate aerosols over nitrate aerosols. However, time slices using 2090 aerosol emissions also use 2090 chemistry emissions: those oxidants which have their concentration driven by emissions will therefore have high burdens anyway, independent of simulated climate. To disentangle the effects of
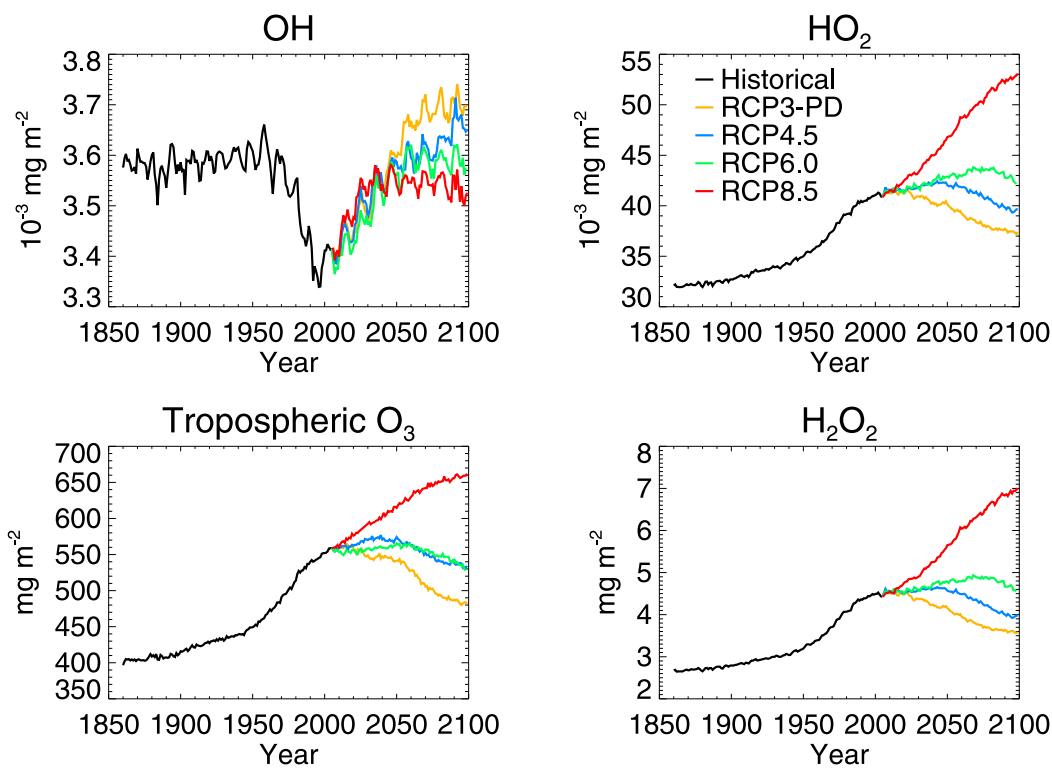

Figure 15. Time series of global and annual averaged burdens $\left(\mathrm{mg} \mathrm{m}^{-2}\right)$ of chemical species involved in the oxidation of sulphur dioxide and dimethyl sulphide in HadGEM2-ES CMIP5 simulations. Historical simulation is shown in black, and the four RCP simulations are shown in color. 

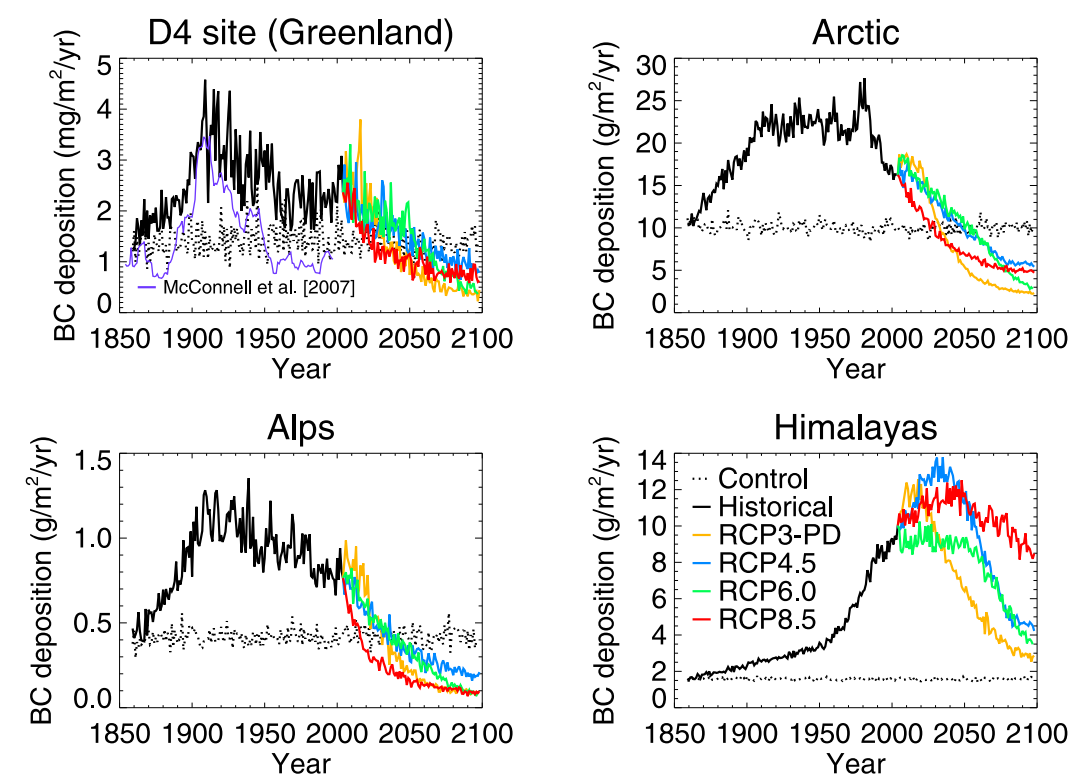

Figure 16. Deposition flux of fossil fuel black carbon (in $\mathrm{mg}[\mathrm{C}] \mathrm{m}^{-2} \mathrm{yr}^{-1}$ or $\mathrm{g}[\mathrm{C}] \mathrm{m}^{-2} \mathrm{yr}^{-1}$ ) over the $\mathrm{D} 4$ site (western central Greenland), the Arctic, Alps, and Himalayas. The control simulation is shown as a dashed black line, the historical simulation is shown as a solid black line, and the four RCP simulations are shown in color. For the D4 site, the 10 year running mean of black carbon deposition flux from ice core measurements by McConnell et al. [2007] is shown as a solid purple line.

emissions and temperature on oxidants, the simulations with aerosol and chemistry emissions fixed at 2090 levels, initialized from either a 1860 or 2090 climate, are analyzed further. Burdens of sulphur cycle oxidants in those simulations are shown in Table 3. Emissions being fixed, increased atmospheric temperatures decrease the burden of $\mathrm{OH}$ but increases the burden of the other oxidants. The increase in ozone burden goes against the expectation of faster ozone removal in a warmer world, mostly because of chemical destruction into $\mathrm{OH}$ when reacting with increased water vapor content [Stevenson et al., 2006]. Liao et al. [2009] simulate a $15 \%$ decrease in ozone burden between simulations driven with present-day and 2100 climate. However, they do not account for increases in stratosphere-troposphere exchange with global warming [Butchart et al., 2006]. Results shown in Table 3 suggest that in HadGEM2-ES additional ozone input from the stratosphere more than compensates for the enhanced destruction of ozone in the troposphere. Stevenson et al. [2006] show that the existence and strength of such a compensation is model dependent. As $75 \%$ of total oxidation of $\mathrm{SO}_{2}$ happens in the aqueous phase with ozone and hydrogen peroxide, the increase in their burdens simulated in HadGEM2-ES means that $\mathrm{SO}_{2}$ is oxidized more efficiently in the warmer 2090 climate than in the colder 1860 climate. Less ammonia remains available after ammonium sulphate formation to form ammonium nitrate, thus decreasing the impact of nitrate on anthropogenic AOD and forcing.

\subsection{Fossil Fuel Black Carbon}

[44] The direct forcing of FFBC at the TOA in HadGEM2-ES is $+0.2 \mathrm{~W} \mathrm{~m}^{-2}$ in all-sky and $+0.1 \mathrm{~W} \mathrm{~m}^{-2}$ in clear-sky conditions, suggesting a significant positive forcing from FFBC aerosols overlying clouds. At the surface, the all-sky and clear-sky estimates are -0.3 and $-0.4 \mathrm{~W} \mathrm{~m}^{-2}$, respectively. HadGEM2-ES does not include the darkening of snow and ice surfaces by black carbon deposition [Flanner et al., 2007], which is regulated by changes in black carbon deposition in glaciated regions and changes in snow and ice area. Figure 16 shows time series of deposition rates of FFBC over the D4 drilling site in western central Greenland $\left(71.4^{\circ} \mathrm{N}, 44.0^{\circ} \mathrm{W}\right)$ and in the Arctic, the Alps, and the Himalayas. These time series are mainly driven by time series of FFBC emissions shown in Figure 1. For the time series at the D4 site, Figure 16 also shows BC deposition fluxes calculated from ice core measurements of BC concentration in ice taken at the same location [McConnell et al., 2007; McConnell, 2010]. Measurements are represented by a 10 year running mean to remove the year-to-year variability that cannot be reproduced from the decadal data sets of CMIP5 emissions. Measurements are for total BC, but McConnell et al. [2007] demonstrate that trends in total BC are due to the fossil fuel component. Observed and modeled trends are in good agreement. BC deposition increases threefold from 1860, peaks in the period 1900-1920, then decreases strongly until 2100 in the model under all RCPs. Deposition after 2030-2050 is smaller than in 1860. Compared to observations, the model overestimates BC deposition fluxes by a factor 1.6 over the period 1850-2000, and a factor 2 for 1960-2000. The long residence time of FFBC in HadGEM2-ES causes the overestimation. The decrease in FFBC deposition in the Arctic only starts in the 1980s. Differences in the shape of Arctic and D4 time series suggest that different regions of the Arctic are influenced by different emitting regions, as expected from atmospheric transport [Reddy and Boucher, 2007]. Modeled time series for the Alps follow the trend simulated for Greenland. The strength of the FFBC darkening of snow in the Arctic and the Alps is therefore expected to have reached its peak in the 20th 
century and will decrease to levels below 1860 in the mid21 st century.

[45] The Himalayas, mainly affected by South Asian emissions, show a different time series. Black carbon depositions have remained small until 1950 and have then increased rapidly to peak at up to 7 times 1860 levels in 2000-2030 depending on scenario. In spite of large decreases in the 21 st century, deposition rates in 2100 remain larger than in 1860 and, for the RCP8.5 scenario, larger than in 2000. The snow darkening effect in the Himalayas may not have yet reached its maximum strength and may persist well into the 21 st century.

\section{Conclusion}

[46] The CMIP5 simulations performed with HadGEM2ES present the opportunity to revisit the estimates of aerosol forcing using a state-of-the-art Earth system model with updated aerosol and chemistry emissions. Anthropogenic aerosols typically follow the time series of their prescribed CMIP5 emissions, increasing rapidly from 1950, peaking in the period 1980-2020, and decreasing for the remainder of the 21 st century. The direct and first indirect forcings at the TOA and surface follow similar trends. Knowing which RCP scenario better represents future aerosol emissions will therefore be of key importance. At first glance, these findings could be interpreted in favor of representing aerosols in climate models as fixed climatologies, scaled with emission changes. Although this approach is not without merit, this study has presented two-way aerosol-climate interactions which can only be represented with interactive aerosols. The simulated climate affects aerosols even in the absence of emission changes: sulphate and nitrate burdens and forcings depend on climate through changes in the oxidizing properties of the atmosphere; aerosol residence times react to changes in clouds; sea salt increases as sea ice extent gets smaller. Both emission and climate-induced changes will in turn affect climate by modulating the strength of the aerosol forcing.

[47] The inclusion of ammonium nitrate aerosols does not increase aerosol forcing much before 2000, but mitigates its decrease in the 21 st century, with the aerosol forcing remaining above 1950 levels in 2090. Nitrate becomes an important aerosol species in Europe and Asia, contributing up to two thirds of the globally averaged anthropogenic optical depth in 2090. Indeed, many recent measurements studies in urban environment have shown that nitrate already dominates aerosol mass [Jimenez et al., 2009; Haywood et al., 2008]. The impact of nitrate in 2090 depends on the relative variations in sulphur dioxide and ammonia emissions, and is maximized by large decreases in sulphur dioxide emissions and large increases in ammonia emissions. However, temperature-driven increases in sulphur cycle oxidants, especially hydrogen peroxide and ozone, lessen the impact of decreases in sulphur dioxide emissions by allowing more sulphate aerosols to be formed. In addition to the importance of including nitrate aerosols in future projections of climate change, large nitrate concentrations have regional air quality implications. Current air quality policies target sectors that emit sulphur dioxide, such as energy generation and transport. The emphasis may need to move to sectors emitting ammonia, such as agriculture. The RCP scenarios are the products of independent models and three out of the four scenarios simulate an increase in ammonia emissions linked to agriculture. Changes in nitrogen deposition can also benefit or impair ecosystem productivity, depending on the initial balance of nutrients [Galloway et al., 2004].

[48] Modeled aerosol residence times increase in the future, against the expectation of a more efficient wet removal by increased precipitation. Simulated decreases in cloud water concentrations between $50^{\circ} \mathrm{N}$ and $50^{\circ} \mathrm{S}$ lessen the likelihood of colocation between aerosols and clouds, which leads to a suppression of wet removal processes by climate change.

[49] Finally, deposition rates of FFBC aerosols onto snow and ice surfaces vary throughout the 1860-2100 period depending on the region considered. The Arctic, Greenland, and the Alps have experienced peak rates during the 20th century and rates have been decreasing since at least 1980 . In the Himalayas, HadGEM2-ES simulations suggest that deposition rates keep increasing until 2030. The associated forcing due to snow darkening is not represented in the model but may remain strong in the Himalayas for the next forty years.

[50] This paper presented general results from the CMIP5 simulations, but more targeted analyses are ongoing, from quantifying feedbacks involving mineral dust and DMS to assessing the importance of aerosols in the surface energy budget. It will be interesting to see how these results will change with the inclusion of a new generation modal aerosol scheme in HadGEM3. The UKCA-MODE model simulates not only aerosol mass, but also aerosol number [Mann et al., 2010]. Processes that affect aerosol mass without affecting aerosol number, and the other way around, can therefore be properly represented. This is important when representing nucleation, and simulating cloud condensation nuclei and aerosol indirect effects [Merikanto et al., 2009].

\section{Appendix A: Aerosol Schemes in HadGEM2}

[51] The aerosol module of HadGEM2 is called the Coupled Large-scale Aerosol Simulator for Studies In Climate (CLASSIC). It contains numerical representations for up to eight tropospheric aerosol species: ammonium sulphate, mineral dust, sea salt, fossil fuel black carbon, fossil fuel organic carbon, biomass burning aerosols, secondary organic (also called biogenic), and ammonium nitrate aerosols. Although each species is associated with a dedicated scheme, some aspects are shared. Emissions or chemical production of mineral dust, sea salt, and nitrate aerosols are interactive, as described below. Emissions for the other species or their precursors are from CMIP5 data sets. Transported species experience boundary layer and convective mixing and are removed by dry and wet deposition. Wet deposition by largescale precipitation is corrected for reevaporation of precipitation: tracer mass is transferred from a dissolved mode to an accumulation mode in proportion of reevaporated precipitation. For convective precipitation, accumulation mode aerosols are removed in proportion to the simulated convective mass flux.

[52] Ammonium sulphate aerosols are part of the interactive sulphur cycle of HadGEM2-ES, as described by Jones et al. [2001] and Roberts and Jones [2004]. The cycle starts with emissions of sulphur dioxide $\left(\mathrm{SO}_{2}\right)$ and dimethyl sulphide (DMS), the latter being provided by the ocean 
biogeochemistry module which simulates plankton concentrations interactively. $\mathrm{SO}_{2}$ and DMS are prognostic tracers of the atmosphere model and are oxidized into sulphate $\left(\mathrm{SO}_{4}^{\overline{\overline{ }}}\right)$ by the hydroxyl radical $(\mathrm{OH})$, hydrogen peroxide $\left(\mathrm{H}_{2} \mathrm{O}_{2}\right)$, the peroxide radical $\left(\mathrm{HO}_{2}\right)$ and ozone $\left(\mathrm{O}_{3}\right)$. The UKCA tropospheric chemistry model (O'Connor et al., manuscript in preparation, 2011), called every time step of the atmosphere model, provides the interactive concentrations of these oxidants. A short description of the chemistry model is given below. Wet oxidation by ozone is the dominant pathway, representing $50 \%$ of total oxidation, with dry oxidation by $\mathrm{OH}$ and wet oxidation by $\mathrm{H}_{2} \mathrm{O}_{2}$ sharing equally the other half. $\mathrm{SO}_{4}^{=}$is represented by three prognostic tracers, representing the Aitken and accumulation modes, and a mode for sulphate dissolved in cloud droplets. Mass is exchanged between those modes by nucleation (accumulation to dissolved mode), evaporation and reevaporation (dissolved to accumulation mode), coagulation and mode merging (Aitken to accumulation mode), and diffusion (Aitken to dissolved mode). Nucleation and diffusion are described by Jones et al. [2001] and are applied to all hygroscopic HadGEM2 aerosol species. Nucleation of accumulation mode aerosols into the dissolved mode is assumed to happen quickly compared to the model time step, so accumulation mode aerosols in the cloudy part of the grid box instantaneously enter the dissolved mode and, conversely, dissolved mode aerosols are instantaneously converted into accumulation mode aerosols in the cloud-free part of the grid box. Cloud fraction is therefore the controlling parameter of that process. Diffusion of Aitken mode aerosols is slower and is computed from the cloud liquid water content, cloud droplet number concentration, and a fixed diffusion coefficient [Jones et al., 2001]. The model also includes a parameterization of the condensation of sulphuric acid $\left(\mathrm{H}_{2} \mathrm{SO}_{4}\right)$ onto Aitken and accumulation modes. Both mode merging and condensation of $\mathrm{H}_{2} \mathrm{SO}_{4}$ are recent additions to the sulphur cycle, described by Bellouin et al. [2007]. Finally, the scheme does not partition sulphate into sulphuric acid and ammonium sulphate: sulphate mass is assumed to be fully in the form of ammonium sulphate.

[53] Mineral dust aerosol modeling is described by Woodward [2001], with revisions described by Bellouin et al. [2007]. Emissions are computed interactively and depend on vegetation fraction, soil roughness length and moisture, and near-surface wind speeds. The horizontal flux is calculated for nine size bins covering particle radii from 0.0316 to $1000 \mu \mathrm{m}$. The vertical flux into the atmosphere is then obtained from the horizontal flux using equation (1) of Woodward [2001] and partitioned across six size bins, covering radii from 0.0316 to $31.6 \mu \mathrm{m}$. These six size bins are then transported and experience deposition through gravitational settling, turbulent mixing, and below-cloud scavenging.

[54] The sea-salt aerosol scheme is described by Jones et al. [2001] and is a diagnostic scheme: its number concentration is computed over open ocean grid boxes at each time step depending on the instantaneous near-surface wind speed. Sea-salt aerosols are not transported nor deposited.

[55] The fossil fuel black carbon (FFBC) aerosol scheme is described by Roberts and Jones [2004]. It involves three prognostic tracers representing fresh, aged, and in-cloud modes. Ageing is represented as an exponential decay with an $e$-folding rate of 1 day. FFBC aerosols are assumed to be hydrophobic and do not exert indirect effects. They are assumed to be interstitial within clouds and as such experience wet deposition after diffusional capture by cloud droplets as described in the appendix of Roberts and Jones [2004].

[56] The biomass burning aerosol scheme is described by Davison et al. [2004] with improvements described by Bellouin et al. [2007]. In contrast to most existing aerosol modules, which simulate biomass burning black carbon independently from biomass burning organic carbon, CLASSIC uses biomass burning tracers representing the sum of these two components. Biomass burning aerosol mass is distributed over three modes: fresh, aged, and dissolved in cloud droplets. Mass is emitted into the fresh mode and later converted into a hygroscopic aged mode with a short $e$-folding time scale of $6 \mathrm{~h}$ [Abel et al., 2003]. Upon ageing, biomass burning mass is increased by a factor of 1.62 to represent condensation of volatile organic compounds. This factor is chosen to decrease the mass fraction of black carbon from $8.75 \%$ in the fresh mode to $5.4 \%$ in the aged mode, following aircraft observations by Abel et al. [2003].

[57] The fossil fuel organic carbon scheme also uses three tracers, representing the fresh, aged, and dissolved modes. Ageing from fresh to aged mode is represented as an exponential decay with a $e$-folding time scale of 1 day.

[58] Secondary organic aerosols represent biogenic aerosols from terpene emissions by vegetation. This is a climatology of monthly three-dimensional mass mixing ratios, taken from the chemistry-transport model STOCHEM [Derwent et al., 2003]. The climatology remains the same for all simulated years.

[59] The nitrate aerosol scheme is a recent addition to CLASSIC and is described here. Ammonium nitrate, $\mathrm{NH}_{4} \mathrm{NO}_{3}$, derives from the equilibrium reaction

$$
\mathrm{HNO}_{3}(g)+\mathrm{NH}_{3}(g) \rightleftharpoons \mathrm{NH}_{4} \mathrm{NO}_{3}
$$

where $\mathrm{HNO}_{3}$ and $\mathrm{NH}_{3}$ are nitric acid and ammonia gases, respectively. $\mathrm{HNO}_{3}$ concentrations are provided by the UKCA tropospheric chemistry scheme (O'Connor et al., manuscript in preparation, 2011), which is summarized below. $\mathrm{NH}_{3}$ is a variable of the atmosphere model and is depleted upon formation of ammonium sulphate. Formation of ammonium sulphate therefore takes priority over that of ammonium nitrate. The reaction between $\mathrm{HNO}_{3}$ and $\mathrm{NH}_{3}$, and the phase of the resulting nitrate aerosol, depend strongly on relative humidity and temperature. In CLASSIC, this dependence is parameterized by computing the dissociation constant, denoted $\mathrm{k}_{p}$ in $\left(\text { molecules per } \mathrm{cm}^{3}\right)^{2}$, of reaction (A1). The calculation of $\mathrm{k}_{p}$ is different for relative humidities above and below the temperature-dependent deliquescence relative humidity (DRH). First, DRH is computed as

$$
\mathrm{DRH}=\exp \left(\frac{618.3}{T}-2.551\right)
$$

where $T$ is the temperature (K). For relative humidities lower than $\mathrm{DRH}, \mathrm{k}_{p}$ depends only on temperature following

$$
k_{p}=T^{-6.025} \exp \left(118.87-\frac{24084}{T}\right)
$$


Table A1. Parameters Describing Aerosol Components in HadGEM2 and the Resulting Aerosol Optical Properties ${ }^{\mathrm{a}}$

\begin{tabular}{|c|c|c|c|c|c|c|}
\hline Aerosol Component & $r_{0}$ & $\sigma$ & Density & $m$ & $k_{\text {ext }}$ & $\varpi_{0}$ \\
\hline Accumulation sulphate & 0.095 & 1.4 & 1769 & $1.53-10^{-7} i$ & $3.1,5.8,182.6$ & 1.00 \\
\hline Aitken sulphate & 0.0065 & 1.3 & 1769 & $1.53-10^{-7} i$ & $0.001,0.004,1.1$ & 1.00 \\
\hline FF black carbon & 0.04 & 2.0 & 1900 & $1.75-0.44 i$ & 5.4 & 0.41 \\
\hline Sea-salt film & 0.1 & 1.9 & 2165 & $1.55-10^{-7} i$ & $3.0,6.9,101.7$ & 1.00 \\
\hline Sea-salt jet & 1.0 & 2.0 & 2165 & $1.55-10^{-7} i$ & $0.2,0.5,9.7$ & 1.00 \\
\hline Fresh biomass & 0.10 & 1.30 & 1350 & $1.55-0.029 i$ & $4.2,4.6,8.8$ & $0.84,0.85,0.92$ \\
\hline Aged biomass & 0.12 & 1.30 & 1350 & $1.54-0.018 i$ & $5.1,6.9,16.7$ & $0.91,0.93,0.97$ \\
\hline Biogenic & 0.095 & 1.50 & 1300 & $1.43-0.0 i$ & $3.5,3.8,19.1$ & 1.0 \\
\hline Fresh FF organic carbon & 0.10 & 1.30 & 1350 & $1.54-0.006 i$ & $3.7,4.1,8.4$ & $0.96,0.97,0.98$ \\
\hline Aged FF organic carbon & 0.12 & 1.30 & 1350 & $1.54-0.006 i$ & $5.0,6.8,16.6$ & $0.97,0.98,0.99$ \\
\hline Accumulation nitrate & 0.095 & 1.40 & 1725 & $1.61-10^{-8} i$ & $4.2,8.5,211$ & 1.00 \\
\hline Mineral Dust Division & \multicolumn{2}{|c|}{ Size Range } & Density & $m$ & $k_{\text {ext }}$ & $\varpi_{0}$ \\
\hline Division 1 & \multicolumn{2}{|c|}{$0.0316-0.1$} & 2650 & $1.52-0.0015 i$ & 0.7 & 0.98 \\
\hline Division 2 & \multicolumn{2}{|c|}{$0.1-0.316$} & 2650 & $1.52-0.0015 i$ & 3.7 & 0.99 \\
\hline Division 3 & \multicolumn{2}{|c|}{$0.316-1.0$} & 2650 & $1.52-0.0015 i$ & 1.0 & 0.97 \\
\hline Division 4 & \multicolumn{2}{|c|}{$1.0-3.16$} & 2650 & $1.52-0.0015 i$ & 0.3 & 0.93 \\
\hline Division 5 & \multicolumn{2}{|c|}{$3.16-10$} & 2650 & $1.52-0.0015 i$ & 0.07 & 0.82 \\
\hline Division 6 & \multicolumn{2}{|c|}{$10-31.6$} & 2650 & $1.52-0.0015 i$ & 0.02 & 0.65 \\
\hline
\end{tabular}

${ }^{\mathrm{a}} \mathrm{FF}$ stands for fossil fuel. Here $r_{0}$ and $\sigma$ are the median radius (in $\mu \mathrm{m}$ ) and geometric standard deviation of the lognormal size distribution. Mineral dust size distribution is described by six size divisions, and division boundaries (in $\mu \mathrm{m}$ ) are shown. Mass density is given in $\mathrm{kg} \mathrm{m}^{-3}$. Here $m$ is the wavelengthdependent complex refractive index, $k_{\text {ext }}$ is the wavelength-dependent specific extinction coefficient (in $\mathrm{m}^{2} \mathrm{~g}^{-1}$ ) for dry aerosol mass, and $\varpi_{0}$ is the wavelength-dependent single-scattering albedo. All wavelength-dependent quantities are shown at $0.55 \mu \mathrm{m}$ only. For hygroscopic aerosols, $k_{\mathrm{ext}}$ and $\varpi_{0}$ also depend on the relative humidity, and values are given at $0 \%, 60 \%$, and $100 \%$ relative humidity.

For relative humidities higher than $\mathrm{DRH}, \mathrm{k}_{p}$ depends on both temperature and relative humidity, following

$$
\left.k_{p}=\left[p_{1}-p_{2}(1-\mathrm{RH})+p_{3}(1-\mathrm{RH})^{2}\right)\right](1-\mathrm{RH})^{1.75} k_{p}^{1}
$$

where $k_{p}^{1}$ is computed using equation (A3), and $p_{1}, p_{2}$, and $p_{3}$ are temperature-dependent parameters defined as

$$
\begin{aligned}
& p_{1}=T^{19.12} \exp \left(-135.94+\frac{8763}{T}\right) \\
& p_{2}=T^{16.22} \exp \left(-122.65+\frac{9969}{T}\right) \\
& p_{3}=T^{24.46} \exp \left(-182.61+\frac{13875}{T}\right)
\end{aligned}
$$

This formulation is by Mozurkewich [1993] and is currently used in the European Monitoring and Evaluation Programme (EMEP) Unified Model (http://www.emep.int/UniDoc). This parameterization is less expensive than solving explicitly the thermodynamic equilibrium involved in nitrate formation and as such fits well the requirements for long integrations of complex and high-resolution Earth system models like HadGEM2-ES.

[60] Denoting concentrations (molecules per $\mathrm{cm}^{3}$ ) with brackets and defining $\left[\mathrm{NH}_{3}\right]$ and $\left[\mathrm{HNO}_{3}\right]$ as total concentrations of ammonia and nitric acid (both as gas and combined into ammonium nitrate), respectively, the equilibrium concentration of ammonium nitrate is computed by solving the following quadratic equation:

$$
\begin{aligned}
{\left[\mathrm{NH}_{4} \mathrm{NO}_{3}\right]=} & \frac{1}{2}\left\{\left[\mathrm{NH}_{3}\right]+\left[\mathrm{HNO}_{3}\right]-\left[\left(\left[\mathrm{NH}_{3}\right]+\left[\mathrm{HNO}_{3}\right]\right)^{2}\right.\right. \\
& \left.\left.-4\left(\left[\mathrm{NH}_{3}\right]\left[\mathrm{HNO}_{3}\right]-k_{p}\right)\right]^{\frac{1}{2}}\right\}
\end{aligned}
$$

if $\left[\mathrm{NH}_{3}\right]\left[\mathrm{HNO}_{3}\right]>k_{p}$,

$$
\left[\mathrm{NH}_{4} \mathrm{NO}_{3}\right]=0
$$

otherwise, which would correspond to dissociation of ammonium nitrate if $\left[\mathrm{NH}_{4} \mathrm{NO}_{3}\right]$ was nonzero at the previous model time step. Finally, concentrations of $\left[\mathrm{NH}_{3}\right]$ and $\left[\mathrm{HNO}_{3}\right]$ are depleted or replenished to account for ammonium nitrate formation or dissociation, respectively. Chemical production of nitrate, as given in equation (A8), goes into an accumulation mode. Cloud formation transfers some of the accumulation mode mass into a dissolved mode, and evaporation and reevaporation transfer mass from the dissolved back to the accumulation mode.

[61] As noted above, sulphur cycle oxidants $\left(\mathrm{OH}, \mathrm{H}_{2} \mathrm{O}_{2}\right.$, $\mathrm{HO}_{2}$, and $\left.\mathrm{O}_{3}\right)$ and nitric acid $\left(\mathrm{HNO}_{3}\right)$ are provided to the aerosol scheme by the UKCA tropospheric chemistry model. This model is described in detail by O'Connor et al. (manuscript in preparation, 2011) and a short summary is given here. The chemistry model represents the chemistry of 41 chemical species, of which 25 are transported tracers. The chemical solver is an explicit iterative backward Euler approach with a chemical time step of $5 \mathrm{~min}$. The model describes odd oxygen $\left(\mathrm{O}_{x}\right)$, nitrogen $\left(\mathrm{NO}_{y}\right)$, hydrogen $\left(\mathrm{HO}_{x}\right)$, and carbon monoxide $(\mathrm{CO})$ chemistry with near-explicit treatment of methane $\left(\mathrm{CH}_{4}\right)$, ethane $\left(\mathrm{C}_{2} \mathrm{H}_{6}\right)$, propane $\left(\mathrm{C}_{3} \mathrm{H}_{8}\right)$, and acetone $\left(\mathrm{Me}_{2} \mathrm{CO}\right)$ degradation (including formaldehyde (HCHO), acetaldehyde (MeCHO), peroxy acetyl nitrate (PAN), and peroxy propionyl nitrate (PPAN)). This chemistry is similar to that described by Law et al. [1998]. The model accounts for 25 photolytic reactions and 96 molecular reactions. $\mathrm{HNO}_{3}$ is generated through the inorganic chemistry and is destroyed by dry and wet deposition, photolysis, and reaction with $\mathrm{OH}$. Treatment of heterogeneous chemistry is not included, thus heterogeneous reactions between $\mathrm{NO}_{3}$ and $\mathrm{N}_{2} \mathrm{O}_{5}$ are not represented. The model is applied across all layers of the atmosphere models, reaching $39 \mathrm{~km}$. However, to account for missing processes in 
stratospheric chemistry, $\mathrm{O}_{3}, \mathrm{CH}_{4}$, and $\mathrm{NO}_{y}$ are relaxed to time-varying climatologies above the tropopause.

[62] The direct radiative effect due to scattering and absorption of radiation by all eight aerosol species represented in the model is included. The semidirect effect, whereby aerosol absorption tends to change cloud formation by warming the aerosol layer, is thereby included implicitly. Wavelength-dependent specific scattering and absorption coefficients are obtained using Mie calculations from prescribed size distributions and refractive indices, as given in Table A1. Sets of wavelength-dependent complex refractive indices are taken from Toon et al. [1976] for ammonium sulphate and sea salt, World Climate Research Program [1986] for fossil fuel black carbon, Haywood et al. [2003] for biomass burning, Jarzembski et al. [2003], Gosse et al. [1997], and Weast [1977] for ammonium nitrate, Balkanski et al. [2007] for mineral dust, and Lund-Myhre and Nielsen [2004] for biogenic aerosols. The real part of the refractive index of fossil fuel organic carbon is taken to be equal to that of biomass burning, with the imaginary part set to $-0.006 i$ for all wavelengths. In addition, hydrophilic species experience hygroscopic growth, whereby the modal radius increases with increasing relative humidity, leading to an increase in specific extinction compared to the dry aerosol. Hygroscopic growth is parameterized following Fitzgerald [1975] for sulphate, sea-salt, and nitrate aerosols; Haywood et al. [2003] for biomass burning aerosols, with fossil fuel organic carbon aerosols assumed to follow the same growth rate; and Varutbangkul et al. [2006] for biogenic aerosols. Finally, all aerosol species except mineral dust and fossil fuel black carbon are considered to be hydrophilic, act as cloud condensation nuclei, and contribute to both the first and second indirect effects on clouds, treating the aerosols as an external mixture. Jones et al. [2001] detail the parameterization of the indirect effects used in HadGEM2-ES. The cloud droplet number concentration (CDNC) is calculated from the number concentration of the accumulation and dissolved modes of hygroscopic aerosols. For the first indirect effect, the radiation scheme uses the CDNC to obtain the cloud droplet effective radius. For the second indirect effects, the large-scale precipitation scheme uses the CDNC to compute the autoconversion rate of cloud water to rainwater.

[63] Acknowledgments. The authors thank J. R. McConnell of the Desert Research Institute in Reno, Nevada, for kindly supplying the ice core data shown in Figure 16 and helping with the analysis. Yves Balkanski and two anonymous reviewers are thanked for their constructive comments. This work was supported by the Joint DECC/Defra Met Office Hadley Centre Climate Programme (GA01101) and by EUCAARI (European Integrated project on Aerosol Cloud Climate and Air Quality Interactions) grant $036833-2$.

\section{References}

Abel, S. J., J. M. Haywood, E. J. Highwood, J. Li, and P. R. Buseck (2003), Evolution of biomass-burning aerosol properties from an agricultural fire in southern Africa, Geophys. Res. Lett., 30(15), 1783, doi:10.1029/ 2003 GL017342.

Adams, P. J., J. H. Seinfeld, D. Koch, L. Mickley, and D. Jacob (2001), General circulation model assessment of direct radiative forcing by the sulfate-nitrate-ammonium-water inorganic aerosol system, J. Geophys. Res., 106, 1097-1111.

Allan, R. P., M. J. Woodage, S. F. Milton, M. E. Brooks, and J. M. Haywood (2011), Examination of longwave radiative bias in general circulation models over North Africa during May-July, Q. J. R. Meteorol. Soc., $137,1179-1192$.
Andres, R. J., and A. D. Kasgnoc (1998), A time-averaged inventory of subaerial volcanic sulfur emissions, J. Geophys. Res., 103, 25,251-25,261.

Balkanski, Y., M. Schulz, T. Claquin, and S. Guibert (2007), Reevaluation of mineral aerosol radiative forcing suggests a better agreement with satellite and AERONET data, Atmos. Chem. Phys., 7, 81-95.

Bauer, S. E., D. Koch, N. Unger, S. M. Metzger, D. T. Shindell, and D. G. Streets (2007), Nitrate aerosols today and in 2030: A global simulation including aerosols and tropospheric ozone, Atmos. Chem. Phys., 7, 5043-5059, doi:10.5194/acp-7-5043-2007.

Bellouin, N., O. Boucher, J. Haywood, C. Johnson, A. Jones, J. Rae, and S. Woodward (2007), Improved representation of aerosols for HadGEM2, Hadley Cent. Tech. Note 73, 43 pp., Met Off. Hadley Cent., Exeter, U. K.

Bellouin, N., A. Jones, J. Haywood, and S. Christopher (2008), Updated estimate of aerosol direct radiative forcing from satellite observations and comparison against the Hadley Centre climate model, J. Geophys. Res., 113, D10205, doi:10.1029/2007JD009385.

Bony, S., et al. (2006), How well do we understand and evaluate climate change feedback processes?, J. Clim., 19, 3445-3482.

Bouwman, A. F., D. S. Lee, W. A. H. Asman, F. J. Dentener, K. W. Van Der Hoek, and J. G. J. Olivier (1997), A global high-resolution emission inventory for ammonia, Global Biogeochem. Cycles, 11, 561-587.

Butchart, N., et al. (2006), Simulations of anthropogenic change in the strength of the Brewer-Dobson circulation, Clim. Dyn., 27, 727-741.

Clarke, L., J. Edmonds, H. Jacoby, H. Pitcher, J. Reilly, and R. Richels (2007), Scenarios of greenhouse gas emissions and atmospheric concentrations, report, 154 pp., U.S. Clim. Change Sci. Program, Washington, D. C.

Collins, W. J., et al. (2011), Development and evaluation of an Earthsystem model-HadGEM2, Geophys. Model Dev., 4, 997-1062.

Davison, P. S., D. L. Roberts, R. T. Arnold, and R. N. Colvile (2004), Estimating the direct radiative forcing due to haze from the 1997 forest fires in Indonesia, J. Geophys. Res., 109, D10207, doi:10.1029/2003JD004264.

Derwent, R. G., W. J. Collins, M. E. Jenkin, C. E. Johnson, and D. S. Stevenson (2003), The global distribution of secondary particulate matter in a 3D Lagrangian chemistry transport model, J. Atmos. Chem., 44, 57-95.

Feng, Y., and J. E. Penner (2007), Global modeling of nitrate and ammonium: Interaction of aerosols and tropospheric chemistry, J. Geophys. Res., 112, D01304, doi:10.1029/2005JD006404.

Fitzgerald, J. W. (1975), Approximation formulas for the equilibrium size of an aerosol particle as a function of its dry size and composition and the ambient relative humidity, J. Appl. Meteorol., 14, 1044-1049.

Flanner, M. G., C. S. Zender, J. T. Randerson, and P. Rasch (2007), Presentday climate forcing and response from black carbon in snow, J. Geophys. Res., 112, D11202, doi:10.1029/2006JD008003.

Formenti, P., W. Elbert, W. Maenhaut, J. Haywood, S. Osborne, and M. O. Andreae (2003), Inorganic and carbonaceous aerosols during the Southern African Regional Science Initiative (SAFARI 2000) experiment: Chemical characteristics, physical properties, and emission data for smoke from African biomass burning, J. Geophys. Res., 108(D13), 8488, doi:10.1029/ 2002JD002408

Forster, P. M., et al. (2007), Changes in atmospheric constituents and in radiative forcing, in Climate Change 2007: The Physical Science Basis: Working Group I Contribution to the Fourth Assessment Report of the Intergovernmental Panel on Climate Change, edited by S. Solomon et al.., pp. 129-234, Cambridge Univ. Press, New York.

Fujino, J., et al. (2006), Multigas mitigation analysis on stabilization scenarios using AIM global model: Multigas mitigation and climate policy, Energy J., 3, 343-354.

Galloway, J. N., et al. (2004), Nitrogen cycles: Past, present, and future, Biogeochemistry, 70, 153-226.

Gosse, S. F., M. Wang, D. Labrie, and P. Chylek (1997), Imaginary part of the refractive index of sulfates and nitrates in the $0.7-2.6-\mu \mathrm{m}$ spectral region, Appl. Opt., 36, 3622-3634.

Haywood, J. M., S. R. Osborne, P. N. Francis, A. Keil, P. Formenti, M. O. Andreae, and P. H. Kaye (2003), The mean physical and optical properties of regional haze dominated by biomass burning aerosol measured from the C-130 aircraft during SAFARI 2000, J. Geophys. Res., 108(D13), 8473, doi:10.1029/2002JD002226.

Haywood, J. M., M. Bush, S. Abel, B. Claxton, H. Coe, J. Crosier, M. Harrison, B. Macpherson, M. Naylora, and S. Osborne (2008), Prediction of visibility and aerosol within the operational Met Office Unified Model. Part II: Validation of model performance using observational data, Q. J. R. Meteorol. Soc., 134, 1817-1832, doi:10.1002/qj.275.

Hjellbrekke, A.-G. (2002), Data report 2000, acidifying and eutrophying compounds, part 2, monthly and seasonal summaries, EMEP/CCC Rep. 7/2002, Norw. Inst. for Air Res., Kjeller, Norw.

Holben, B. N., et al. (2001), An emerging ground-based aerosol climatology: Aerosol optical depth from AERONET, J. Geophys. Res., 106, 9807-9826. Huneeus, N., et al. (2010), Global dust model intercomparison in AeroCom phase I, Atmos. Chem. Phys. Discuss., 10, 3781-3864. 
Isaksen, I. S. A., et al. (2009), Atmospheric composition change: Climatechemistry interactions, Atmos. Environ., 43, 5138-5192.

Jacobson, M. Z. (2001), Global direct radiative forcing due to multicomponent anthropogenic and natural aerosols, J. Geophys. Res., 106, 1551-1568.

Jarzembski, M. A, M. L. Norman, K. A. Fuller, V. Srivastava, and D. R. Cutten (2003), Complex refractive index of ammonium nitrate in the 2-20- $\mu \mathrm{m}$ spectral range, Appl. Opt., 42, 922-930.

Jickells, T. D., et al. (2005), Global iron connections between desert dust, ocean biogeochemistry, and climate, Science, 308, 67-71.

Jimenez, J. L., et al. (2009), Evolution of organic aerosols in the atmosphere, Science, 326, 1525-1529, doi:10.1126/science.1180353.

Jones, A., D. L. Roberts, M. J. Woodage, and C. E. Johnson (2001), Indirect sulphate aerosol forcing in a climate model with an interactive sulphur cycle, J. Geophys. Res., 106, 20,293-20,310.

Jones, A., J. M. Haywood, and O. Boucher (2007), Aerosol forcing, climate response and climate sensitivity in the Hadley Centre climate model, J. Geophys. Res., 112, D20211, doi:10.1029/2007JD008688.

Jones, C., et al. (2011), The HadGEM2-ES implementation of CMIP5 centennial simulations, Geophys. Model Dev., 4, 543-570, doi:10.5194/ gmd-4-543-2011.

Lamarque, J.-F., et al. (2010), Historical (1850-2000) gridded anthropogenic and biomass burning emissions of reactive gases and aerosols Methodology and application, Atmos. Chem. Phys., 10, 7017-7039.

Law, K. S., P.-H. Plantevin, D. E. Shallcross, H. L. Rogers, J. A. Pyle, C. Grouhel, V. Thouret, and A. Marenco (1998), Evaluation of modeled $\mathrm{O}_{3}$ using Measurement of Ozone by Airbus in Service Aircraft (MOZAIC) data, J. Geophys. Res., 103, 25,721-25,737.

Li, W. J., and L. Y. Shao (2009), Observation of nitrate coatings on atmospheric mineral dust particles, Atmos. Chem. Phys., 9, 1863-1871.

Liao, H., and J. H. Seinfeld (2005), Global impacts of gas-phase chemistryaerosol interactions on direct radiative forcing by anthropogenic aerosols and ozone, J. Geophys. Res., 110, D18208, doi:10.1029/2005JD005907.

Liao, H., J. H. Seinfeld, P. J. Adams, and L. J. Mickley (2004), Global radiative forcing of coupled tropospheric ozone and aerosols in a unified general circulation model, J. Geophys. Res., 109, D16207, doi:10.1029/2003JD004456

Liao, H., Y. Zhang, W.-T. Chen, F. Raes, and J. H. Seinfeld (2009), Effect of chemistry-aerosol-climate coupling on predictions of future climate and future levels of tropospheric ozone and aerosols, J. Geophys. Res., 114, D10306, doi:10.1029/2008JD010984.

Lohmann, U., L. Rotstayn, T. Storelvmo, A. Jones, S. Menon, J. Quaas, A. M. L. Ekman, D. Koch, and R. Ruedy (2010), Total aerosol effect: Radiative forcing or radiative flux perturbation?, Atmos. Chem. Phys., 10, 3235-3246.

Lund-Myhre, C., and C. J. Nielsen (2004), Optical properties in the UV and visible spectral region of organic acids relevant to tropospheric aerosols, Atmos. Chem. Phys., 4, 1759-1769.

Malm, W. C., J. F. Sisler, D. Huffman, R. A. Eldred, and T. A. Cahil (1994), Spatial and seasonal trends in particle concentration and optical extinction in the United States, J. Geophys. Res., 99, 1347-1370.

Mann, G. W., K. S. Carslaw, D. V. Spraklen, D. A. Ridley, P. T. Manktelow, M. P. Chipperfield, S. J. Pickering, and C. E. Johnson (2010), Description and evaluation of GLOMAP-mode: A modal global aerosol microphysics model for the UKCA composition-climate model, Geosci. Model Dev., 3, 519-551.

McConnell, J. R. (2010), New directions: Historical black carbon and other ice core aerosol records in the Arctic for GCM evaluation, Atmos. Environ., 44, 2665-2666.

McConnell, J. R., R. Edwards, G. L. Kok, M. G. Flanner, C. S. Zender, E. S. Saltzman, J. R. Banta, D. R. Pasteris, M. M. Carter, and J. D. W Kahl (2007), 20th-century industrial black carbon emissions altered Arctic climate forcing, Science, 317, 1381-1384.

Mercado, L., N. Bellouin, O. Boucher, S. Sitch, C. Huntingford, M. Wild, and P. Cox (2009), Impact of changes in diffuse radiation on the global land carbon sink, Nature, 458, 1014-1017, doi:10.1038/nature07949.

Merikanto, J., D. V. Spracklen, G. W. Mann, S. J. Pickering, and K. S. Carslaw (2009), Impact of nucleation on global CCN, Atmos. Chem. Phys., 9, 8601-8616.

Moss, R. H., et al. (2010), The next generation of scenarios for climate change research and assessment, Nature, 463, 747-756, doi:10.1038/ nature 08823 .

Mozurkewich, M. (1993), The dissociation constant of ammonium nitrate and its dependence on temperature, relative humidity and particle size, Atmos. Environ., Part A, 27, 261-270.

Mueller, S. F. (2003), Seasonal aerosol sulfate trends for selected regions of the United States, J. Air Waste Manage. Assess., 53, 168-184.

Myhre, G., A. Grini, and S. Metzger (2006), Modelling of nitrate and ammonium-containing aerosols in presence of sea salt, Atmos. Chem. Phys., 6, 4809-4821.
Quaas, J., O. Boucher, N. Bellouin, and S. Kinne (2008), Satellite-based estimate of the direct and indirect aerosol climate forcing, J. Geophys. Res., 113, D05204, doi:10.1029/2007JD008962.

Quaas, J., et al. (2009), Aerosol indirect effects - General circulation model intercomparison and evaluation with satellite data, Atmos. Chem. Phys., 9, 8697-8717.

Racherla, P. N., and P. J. Adams (2006), Sensitivity of global tropospheric ozone and fine particulate matter concentrations to climate change, J. Geophys. Res., 111, D24103, doi:10.1029/2005JD006939.

Rae, J. G. L., C. E. Johnson, N. Bellouin, O. Boucher, J. M. Haywood, and A. Jones (2007), Sensitivity of global sulphate aerosol production to changes in oxidant concentrations and climate, J. Geophys. Res., 112, D10312, doi:10.1029/2006JD007826.

Reddy, M. S., and O. Boucher (2007), Climate impact of black carbon emitted from energy consumption in the world's regions, Geophys. Res. Lett., 34, L11802, doi:10.1029/2006GL028904.

Riahi, K., A. Gruebler, and N. Nakicenovic (2007), Scenarios of long-term socio-economic and environmental development under climate stabilization, Technol. Forecast. Soc. Change, 74, 887-935.

Roberts, D. L., and A. Jones (2004), Climate sensitivity to black carbon aerosol from fossil fuel combustion, J. Geophys. Res., 109, D16202, doi:10.1029/2004JD004676.

Rodriguez, M. A., and D. Dabdub (2004), IMAGES-SCAPE2: A modeling study of size- and chemically-resolved aerosol thermodynamics in a global chemical transport model, J. Geophys. Res., 109, D02203, doi:10.1029/2003JD003639.

Schulz, M., et al. (2006), Radiative forcing by aerosols as derived from the AeroCom present-day and pre-industrial simulations, Atmos. Chem Phys., 6, 5225-5246.

Spiro, P. A., D. J. Jacob, and J. A. Logan (1992), Global inventory of sulfur emissions with $1^{\circ} \times 1^{\circ}$ resolution, J. Geophys. Res., 97, 6023-6036.

Stevenson, D. S., et al. (2006), Multimodel ensemble simulations of present-day and near-future tropospheric ozone, J. Geophys. Res., 111, D08301, doi:10.1029/2005JD006338.

Taylor, K. E., R. J. Stouffer, and G. A. Meehl (2009), A summary of the CMIP5 experimental design, report, World Clim. Res. Program, Geneva, Switzerland. [Available at http://cmip-pcmdi.llnl.gov/cmip5/experiment design.html.]

Textor, C., et al. (2006), Analysis and quantification of the diversities of aerosol life cycles within AeroCom, Atmos. Chem. Phys., 6, 1777-1813.

Thomas, M. A., P. Suntharalingam, L. Pozzoli, A. Devasthale, S. Kloster, S. Rast, J. Feichter, and T. M. Lenton (2011), Non-linearity in DMS aerosol-cloud-climate interactions, Atmos. Chem. Phys. Discuss., 11, 15,227-15,253, doi:10.5194/acpd-11-15227-2011.

Toon, O. B., J. B. Pollack, and B. N. Khare (1976), The optical constants of several atmospheric aerosol species: Ammonium sulfate, aluminum oxide, and sodium chloride, J. Geophys Res., 81, 5733-5748.

Usher, C. R., A. E. Michel, and V. H. Grassian (2003), Reactions on mineral dust, Chem. Rev., 103, 4883-4940.

van Dorland, R., F. J. Dentener, and J. Lelieveld (1997), Radiative forcing due to tropospheric ozone and sulfate aerosols, J. Geophys. Res., 102 28,079-28,100.

van Vuuren, D., M. den Elzen, P. Lucas, B. Eickhout, B. Strengers, B. van Ruijven, S. Wonink, and R. van Houdt (2007), Stabilizing greenhouse gas concentrations at low levels: An assessment of reduction strategies and costs, Clim. Change, 81(2), 119-159, doi:10.1007/s/10584-0069172-9.

Varutbangkul, V., et al. (2006), Hygroscopicity of secondary organic aerosols formed by oxidation of cycloalkenes, monoterpenes, sesquiterpenes, and related compounds, Atmos. Chem. Phys., 6, 2367-2388.

Weast, R. C. (1977), CRC Handbook of Chemistry and Physics, 58th ed., CRC Press, Cleveland, Ohio.

West, J. J., A. S. Ansari, and S. N. Pandis (1999), Marginal PM2.5: Nonlinear aerosol mass response to sulfate reductions in the eastern United States, J. Air Waste Manage. Assoc., 49, 1415-1424.

Wild, M. (2009), Global dimming and brightening: A review, J. Geophys. Res., 114, D00D16, doi:10.1029/2008JD011470.

Woodward, S. (2001), Modelling the atmospheric life cycle and radiative impact of mineral dust in the Hadley Centre climate model, J. Geophys. Res., 106, 18,155-18,166.

World Climate Research Programme (1986), A preliminary cloudless standard atmosphere for radiation computation, Rep. WCP-112, $53 \mathrm{pp}$. Geneva, Switzerland

N. Bellouin, O. Boucher, J. Haywood, C. Johnson, A. Jones, and J. Rae, Met Office, Hadley Centre, FitzRoy Road, Exeter, Devon EX1 3PB, UK. (nicolas.bellouin@metoffice.gov.uk) 